\title{
Spatiotemporal trend analysis of recent river water quality conditions in Japan.
}

\section{$\operatorname{AUTHOR}(\mathrm{S}):$}

Luo, Pingping; He, Bin; Takara, Kaoru;

Razafindrabe, Bam H N; Nover, Daniel; Yamashiki, Yosuke

\section{CITATION:}

Luo, Pingping ... [et al]. Spatiotemporal trend analysis of recent river water quality conditions in Japan.. Journal of environmental monitoring : JEM 2011, 13(10): 2819-2829

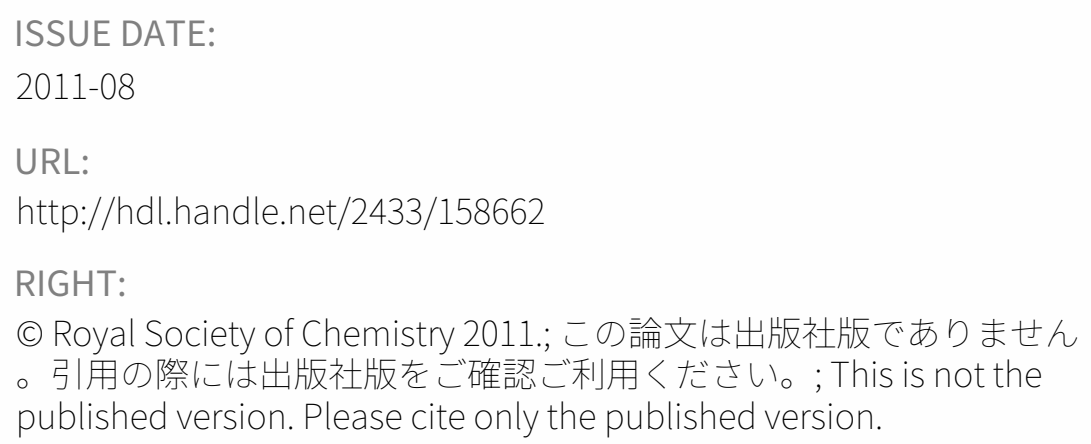




\title{
Spatiotemporal trend analysis of recent river water quality conditions in Japan
}

\author{
Pingping Luo ${ }^{1}$, Bin $\mathrm{He}^{2,3}$, Kaoru Takara ${ }^{3}$, Bam H.N. Razafindrabe ${ }^{4}$, \\ Daniel Nover ${ }^{5}$, Yosuke Yamashiki ${ }^{3}$ \\ ${ }^{1}$ Department of Urban and Environmental Engineering, Graduate School of Engineering, Kyoto \\ University, Japan \\ robertluoping@flood.dpri.kyoto-u.ac.jp \\ ${ }^{2}$ Center for Promotion of Interdisciplinary Education and Research, Educational Unit for Adaptation and \\ Resilience for a Sustainable Society, Kyoto University, Japan \\ hebin@flood.dpri.kyoto-u.ac.jp \\ ${ }^{3}$ Disaster Prevention Research Institute, Kyoto University, Japan \\ ${ }^{4}$ Graduate School of Environment and Information Sciences, Yokohama National University \\ ${ }^{5}$ Department of Civil and Environmental Engineering, University of California, Davis, USA
}

\begin{abstract}
:
In order to promote pollutant monitoring and preservation of water resources, we evaluate the spatiotemporal trends in recent water quality conditions in Japanese rivers. Trend analysis is conducted on the 92 major rivers in Japan using the available water quality data recorded from 1992 to 2005 and the characteristics of major pollutants in these rivers are analyzed. Spatial and temporal analysis of trends for six water quality indicators is conducted using the Mann Kendall test, a non-parametric statistical method. The indicators analyzed are biochemical oxygen demand (BOD), chemical oxygen demand (COD), dissolved oxygen (DO), total nitrogen (TN), total phosphorus (TP) and $\mathrm{pH}$. The majority of sampling locations monitoring BOD, COD, TN and TP show trends toward decreasing concentrations over time. Many sampling locations show increasing DO concentrations. Our results show that water quality in Japanese rivers has improved dramatically over the past decade, although there are still problems in some places, most notably in the Hokkaido, Kanto, Kinki and Kyushu regions. The improvements seen in water quality appear to be the result of improved wastewater treatment and other water quality improvement efforts achieved through government initiative.
\end{abstract}

Keyword: Japan rivers, water quality, Spatiotemporal trend analysis, Mann Kendall 


\section{Introduction}

River water is essential for domestic use, irrigation, industrial production, and numerous other activities. ${ }^{1}$ Anthropogenic impacts directly affect watershed hydrology, ${ }^{2,3}$ the energy balance in water, ${ }^{4}$ and biogeochemical cycling in streams, ${ }^{5}$ all of which influence water quality. All of these impacts are compounded by recent climate change. ${ }^{6}$ Therefore, the monitoring of river water quality is essential both for understanding the current condition of rivers and for managing water quality impairments under various stresses. ${ }^{7-10}$ The analysis of monitoring data using spatial and temporal trends provides numerous insights into water quality conditions that will prove useful to both the private and public sectors.

Japan has made significant efforts to improve river water quality in recent years. Japanese river systems are characterized by relatively short reaches, steep elevation, and higher rainfall intensity than in many other countries. As a consequence, rapid flushing can quickly reduce the concentration of water pollution. In previous research, Yodo River water quality and pollutant loading were investigated ${ }^{11}$ and a river basin-scale surface water quality assessment was conducted for the Fuji River using multivariate statistical tools. ${ }^{12}$ Additionally, water quality impact assessment based on a 200-year record of natural and anthropogenic changes to Lake Shinji, Japan was reported by Yamamuro and Kanai. ${ }^{13}$ Other research discussed water quality in lake environments, including the effect of agriculture on water quality in Lake Biwa ${ }^{14}$ and the water quality change in Lake Ohnuma, Hokkaido. ${ }^{15}$ Impact evaluation of land use and nitrogen budgets on stream water quality in Hokkaido was reported by Woli et al.. ${ }^{16}$ A comparative study of water quality between Indonesia and Japan ${ }^{1}$ provided some preliminary water quality conditions for Japanese rivers. Many other researchers have also conducted focused studies on water quality in specific Japanese rivers or lakes. In recent years, some researchers have developed integrated modeling systems to simulate the water quality condition in Japan. ${ }^{17-21}$ However, few studies have characterized spatial and temporal trends in important water quality indicators on a national scale for Japanese rivers. This kind of nation-wide study is necessary to build coherent environmental policy and direct future monitoring of water quality.

Spatiotemporal trend analysis has seen increased interest in recent years for its ability to generate useful information for researchers and policy makers. ${ }^{22,23}$ Water quality trend analysis was conducted for the Han River basin, ${ }^{24}$ the Nakdong River, ${ }^{25}$ Korea, the Scottish rivers, ${ }^{26}$ the Pinios River, Grecian rivers, ${ }^{27}$ the Jinshui River, Chinese rivers, ${ }^{28}$ the Schuylkill River, USA, ${ }^{29}$ and the Frome River, UK. ${ }^{30}$ There are also many previous studies of water quality trends in lakes, including the Eymir Lake, Turkey, ${ }^{31}$ Lake of the Woods, Canada, ${ }^{32}$ the Laurentian Great Lakes in North America, ${ }^{33}$ and Muskegon Lake, USA. ${ }^{34}$ Variation in water quality in the Chinese Grand Canal, a large artificial river, was reported by Wang. ${ }^{35}$ However, many of the previous studies investigated either spatial variations of water quality using mean values for each monitoring site (e.g., Arheimer and Liden ${ }^{36}$; Donohue et al. ${ }^{37}$ ) or temporal trends for a few selected sites. To our knowledge, no complete spatial and temporal trend assessment for all of Japan has been conducted.

This paper's main objective is to evaluate the spatiotemporal trends in recent water quality condition in Japanese rivers. Datasets of major water quality indices, including biochemical oxygen demand (BOD), chemical oxygen demand (COD), dissolved oxygen (DO), total nitrogen (TN), total phosphorus (TP), and $\mathrm{pH}$, were provided by the Japanese Ministry of Land, 
Infrastructure, Transport and Tourism (MLIT). ${ }^{38}$ Maps showing the concentration trends of these six water quality indices were generated to evaluate the recent condition of Japanese river water quality. The trends in these water quality indices were analyzed using the Mann Kendall trend test for 92 Japanese rivers using data from the past 14 years (1992-2005) in order to provide a better understanding of water quality issues in Japan.

\section{Materials and methods}

\subsection{Description of study site and data collection}

Japan is a country comprised of many islands, located in East Asia with 127.7 million inhabitants in 2008. The total surface area of Japan is $377944 \mathrm{~km}^{2}$ and $70 \%$ to $80 \%$ is covered by forest. It is divided into 10 regions: Hokkaido, Tohoku, Kanto, Chubu, Hokuriku, Kinki, Chugoku, Shikoku, Kyushu and Okinawa. The Japanese government has designated important rivers as "first-class river systems" indicating great social and economic importance that should be prioritized for conservation. By the end of 1998, there were 109 designated first-class river systems. Due to the narrow, mountainous topography in Japan, the rivers are short with steep gradients and deep Vshaped valleys in the high elevation reaches. The Shinano River is the longest river in Japan and the Tone River has the largest catchment area.

By the end of the 1950s, industrialization led to major river water pollution, causing major damage to fisheries in the Edo River, Yodo River, Osaka Bay and Ise Bay. In 1958, under pressure from citizens demanding compensation for damage to fisheries and human health, the government enacted two water quality laws known as the Public Water Quality Protection Law and the Industrial Effluent Water Law. Rapid urbanization toward the end of the 1960s led to serious water pollution, most notably the large-scale red tide in the Sea of Harima which spread to lakes, inner bays and ponds. As a consequence, the Basic Law for Environmental Pollution Control (1967), the Water Pollution Control Law (1970), the Environmental Quality Standards (1970), and the Environmental Agency for Water Quality Management Policies were established. However, the water pollution loading from households increased into the middle of the 1970s. The water quality conditions were then stable and improved in some areas in the 1980s. Several important pieces of environmental legislation were enacted during the 1990s, including laws focused on the promotion of controls for domestic wastewater (1990), protection of the drinking water supply (1994) and protection of headwaters for drinking (1994). These laws were outlined in the Basic Environment Law (1993) and the Basic Environment Plan (1994).

In this study, we selected a total of 92 rivers on the main islands of Japan (Fig. 1). Annual data for $\mathrm{BOD}, \mathrm{COD}, \mathrm{DO}, \mathrm{TN}, \mathrm{TP}$ and $\mathrm{pH}$ averaged in each year were collected from 98 river water quality observation stations located at the mouth of the selected rivers (Table. 1). The period of the collected data is from 1992 to 2005 and they are published in the Water Quality Year Book by the River Bureau of the Japanese Ministry of Land, Infrastructure, Transport and Tourism (MLIT). ${ }^{38}$ Twelve of the selected rivers and 12 sampling stations are in Hokkaido, 11 rivers and 11 stations are in Tohoku, 8 rivers and 8 stations are in Kanto, 9 rivers and 10 stations are in Hokuriku, 9 rivers and 11 are stations in Chubu, 10 rivers and 10 are stations in Kinki, 10 rivers and 10 stations are in Chugoku, 5 rivers and 5 stations are in Shikoku, and 18 rivers and 21 stations are in Kyushu (Table. 2). The land use map is shown in Fig. 2. 


\subsection{Water Quality Variables}

Dissolved oxygen (DO) is a key water quality indicator as it is essential for the survival of fish and other aquatic organisms. Concentrations of DO are governed by oxygen sources and sinks. Oxygen is generated by photosynthetic organisms and atmospheric replenishment and is consumed by bacteria (BOD), degradable chemicals (COD), loss from stream flow and loss from sediment oxygen demand. The trend in DO may be regarded as an indicator of the overall trend in water quality. Biochemical oxygen demand is a measurement of the oxygen that is consumed by bacterial degradation of biodegradable organics in water ${ }^{39}$ and reflects an indirect measurement of the concentration of organic compounds in water. ${ }^{40}$ Total nitrogen includes nitrate- $\mathrm{N}$ and nitrite- $\mathrm{N}$, and total phosphorus is the sum of all phosphorus-containing components in the water. $\mathrm{pH}$ is a measure of the concentration of hydrogens ions in an aqueous solution.

\subsection{Mann Kendall Test}

The Mann Kendall test (MKT) was applied in this study in order to calculate the trend values for $\mathrm{BOD}, \mathrm{COD}, \mathrm{DO}, \mathrm{TN}, \mathrm{TP}$ and $\mathrm{pH}$. MKT is a non-parametric statistical procedure used to test for trends in time series data. ${ }^{41}$ The null hypothesis in the Mann-Kendall test is that the data are independent and randomly ordered, i.e. there is no trend or serial correlation structure in the time-series. ${ }^{42,43}$ For independent and randomly ordered data in a time-series $X_{i}\left\{X_{i}, i=1,2, \ldots\right.$, $\mathrm{n}$ \}, the null hypothesis $H_{0}$ is tested on the observations $X_{i}$ against the alternative hypothesis $H_{l}$, where there is an increasing or decreasing monotonic trend. ${ }^{41}$ Gibert ${ }^{44}$ divided $n$ (number of values) $<10$ and $n \geq 10$ to calculate the normal approximation $Z$. In this study, the time series is 14 years and the number of values is more than 10 . According to the condition of $n \geq 10$, the $S$ variance is described according to equation (1) below:

$$
\operatorname{Var}(S)=\frac{n(n-1)(2 n+5)-\sum_{i=1}^{e} t_{i}\left(t_{i}-1\right)\left(2 t_{i}+5\right)}{18}
$$

Where, $e$ is the number of tied groups and $t_{i}$ is the number of data values in the $i$ th group. The statistical $S$ test is given as follows:

$$
S=\sum_{e=1}^{n-1} \sum_{i=e+1}^{n} \operatorname{sgn}\left(x_{i}-x_{e}\right)
$$

Where,

$$
\operatorname{sgn}(\varphi)=\left\{\begin{array}{cc}
1 & \varphi>0 \\
0 & \varphi=0 \\
-1 & \varphi<0
\end{array}\right.
$$


The normal approximation $\mathrm{Z}$ test by using the statistical value $\mathrm{S}$ and the variance value $\operatorname{Var}(\mathrm{S})$ is written in the following form:

$$
Z=\left\{\begin{array}{ccc}
\frac{S-1}{\sqrt{\operatorname{Var}(S)}} & \text { if } & S>0 \\
0 & \text { if } & S=0 \\
\frac{S+1}{\sqrt{\operatorname{Var}(S)}} & \text { if } & S<0
\end{array}\right.
$$

For the normal approximation $\mathrm{Z}$ test and the cumulative standard normal distribution $\Phi$, if $|Z| \leq Z_{\alpha / 2}$

and $\Phi\left(\mathrm{Z}_{\alpha / 2} \Phi\right)=\alpha / 2$, then the $\mathrm{H}_{0}$ hypothesis is adopted. The $\alpha$ is the probability level of rejecting the null hypothesis $\mathrm{H}_{0}$ when it is true. The $\mathrm{Z}$ value shows the statistical trend. If $\mathrm{Z}<0$, it indicates a decreasing trend and if $\mathrm{Z}>0$ it indicates an increasing trend.

\subsection{Spatial distribution map of MKT results}

Geographic Information System (GIS) was employed for visual demonstration of the spatial distribution of MKT results. There are many widely used GIS software, including the ESRI series, GRASS, HuMap, OpenGIS, and SuperMap Viewer. A free GIS tool developed by Tani Kenji ${ }^{45}$ called MANDARA was employed in this study. It has rich map creation and viewing functions, map drawing functions and other basic spatial operations functions. ${ }^{46}$ Some basic information maps of Japan, China, and the USA are included in the package. Moreover, Microsoft EXCEL files can be directly input into MANDARA.

\section{Result and discussion}

In this section, we will analyze the results of the Mann-Kendall test and characterize the six water quality indicators (BOD, COD, DO, TN, TP and $\mathrm{pH}$ ) including the mean value and recent trend from 1992 to 2005 . For ease of understanding, the following figures show the calculated Z value of MKT using red for positive and green for negative.

\subsection{Trend of BOD, COD, and DO}

As shown in Fig. 3, the sites with the highest average BOD values are located at the rivers near Osaka bay in the Kinki region, the area between the Hiroshima and Okayama prefectures in the Chugoku region, the northwest of Shikoku region and the bay of the Ariake Sea in Kyushu region. The BOD mean value of all these four rivers is over $4 \mathrm{mg} / \mathrm{l}$. The highest BOD value is found at the Yamato River near Osaka bay in Kinki region. Most of the temporal trends of BOD (Fig.3) showed decreasing values, but there are also some increasing trends at several rivers in Kanto region, Kinki region, Chugoku region and Shikoku region. The increasing trend is especially significant in the rivers of Hokkaido region. 
Most of the Hokkaido region is essentially undeveloped and livestock is one of the major factors affecting river water quality. ${ }^{47}$ The increased trend of BOD at the Tokachi River in Hokkaido is mainly the result of domestic pollution from the urban area. The increased trend at the rivers in the north of Hokkaido is primarily caused by urban sewage and agricultural runoff. ${ }^{47}$ The highest average value of BOD in rivers is located in Kinki region, the area between Hiroshima prefecture and Okayama prefecture of Chugoku region and the bay of the Ariake Sea in Kyushu region. It is likely that their high BOD values result from industrial wastewater and urban sewage.

The distribution of average COD values is similar to trends in BOD values (see Fig.4). There are high values at the rivers in Osaka bay and the area between the Hiroshima and the Okayama Prefecture. In the bay of Ariake Sea in Kyushu region, there is an extremely high mean value of COD (over $34 \mathrm{mg} / \mathrm{l}$, which is 3 times the values at other sites). However, the trend in COD at the river in the Ariake Sea bay shows a dramatic decrease in mean value in the recent decade. The largest increasing trend is seen at the river in the southwest of Shikoku region. In Hokkaido region, only the Tokachi River has high average COD values and a high positive trend.

Numerous factors may contribute to the increasing trend in the Tokachi River as the river receives waste-water from dairy facilities, gas works and livestock. Agricultural fertilizers from farms in the area as well as effluent from beet and starch processing factories probably also contribute to declining water quality in the Tokachi River. ${ }^{48,49}$ The high average value in Tokyo bay and Osaka bay may be the result of high population density. It is well known that volcanic eruptions occur often in Nagasaki Prefecture. Additionally, Honmyou River is the most important river in the Nagasaki prefecture of Kyushu region. Volcanic eruptions occurred in 1992, 1993 and 1994 and caused ash containing free $\mathrm{CaO}$ and $\mathrm{CaSO}_{4}$ and $\mathrm{SO}_{2}$ to flow into the Honmyou River with the rainfall. This is likely the largest factor contributing to the high COD values in Honmyou River in these three years.

The mean value of DO in the 92 Japanese rivers does not show much variation. Most average values are approximately $10 \mathrm{mg} / \mathrm{l}$. The greatest decreasing trend is in the Tokachi River in the south of Hokkaido (Fig. 5). Some decreasing trends are located at the Kumano River and Kako River in the Kinki region, the Fuji River in the Kanto region, the Chiyo River and Hino River in the Chugoku region and the Kawauchi River in the Kyushu region. The greatest increasing trend existed in the Tohoku region and Hokuriku region. The small mean value and high decreasing trend of DO in the Tokachi River is caused by the large average values of BOD and COD, and the high increasing trend in COD concentration. The increasing trend of DO concentration seen in the Tohoku region and Hokuriku region is probably caused by declining populations and increasing wastewater treatment standards set by the government.

\subsection{Trend of TN, TP and $\mathrm{pH}$}

There are three main locations with a high average value of TN. These are the rivers in Tokyo bay of Kanto region, Osaka bay of Kinki region and the Ariake Sea bay area of Kyushu region. Despite the high values, TN in these three areas shows a decreasing trend (see Fig.6). With the reduction of farmland and livestock grazing and consequent reductions in nitrogen rich fertilizers may cause the decreasing trend on $\mathrm{TN}^{50}$ The agricultural practices and environmental nitrogen 
input and output peaked in 1985 and then decreased..$^{51}$ In addition to reduced agricultural activity, the decreasing trend of $\mathrm{TN}$ in these three areas corresponds with a period of increasing fertilization efficiency. The Saru River of Hokkaido region showed a doubling of TN over time, but a low value on average. The Rumoi and Kushiro Rivers in Hokkaido region also show increasing trends. Another high trend value was observed at the Saba River in the Yamaguchi prefecture of Chugoku region.

In the rivers of Tokyo bay and Osaka bay, the high loading due to urban sewage is an important factor that likely causes the high mean values of TN. High loading due to urban sewage and the volcanic eruption are likely the main reasons for the high average values at the rivers of the Ariake Sea bay area. The increasing trend in the Saba River is significant but the average TN value is very small. The maximum value of TN concentration is smaller than 1.0 $\mathrm{mg} / \mathrm{l}$. The increasing trend of $\mathrm{TN}$ may be caused by frequent droughts. Although the highest increasing trend values existed in the Saru River of Hokkaido region, the water quality of the Saru River is the best in Japan.

The average value of TP is high in the Tokachi River of the Hokkaido region, the Shikenobu River of Shikoku region, the Ashida River in Chugoku region and the rivers in Tokyo bay of the Kanto region, the Osaka bay of the Kinki region and the Ariake Sea bay area of Kyushu region. However, most of their trends are decreasing (see Fig. 7). An extreme mean value of TP which corresponds with an extreme value of SS is located at the Honmyou River in Kyushu region. The extreme value is three times more than the other values recorded. With respect to the trends in $\mathrm{TP}$, there are 7 stations in the Hokkaido region which showed an increasing trend. Fig. 7 shows high increasing trends at the Tone River of Kanto region and the Kumano River in the Kinki region.

The high mean value of TP and a small increasing trend was found in the Tokachi River. This may be a consequence of drainage from urban sewage, agricultural land, and livestock production facilities. ${ }^{52,53}$ The other rivers in Hokkaido with increasing trends may also be influenced by increased livestock grazing and land use change. Global warming, which is driving earlier and higher snowmelt runoff events probably also affects the increasing trend of $\mathrm{TP}^{54}$ in most major rivers of Hokkaido region. The distribution of mean values of TP were similar to TN in Tokyo bay and Osaka bay, but the TP concentrations are much more elevated at around 0.6 $\mathrm{mg} / \mathrm{l}$ in Osaka bay than $0.5 \mathrm{mg} / \mathrm{l}$ in Tokyo bay. The reason for the high average TP concentrations in the two areas is still not clear. Even if the Kumano River in the Kinki region had a highly increasing trend, the average TP value is very low. High TP values were found in 1992, 1993 and 1994 and correspond to the same periods as the high SS value. The extreme mean value in the Honmyou River of Kyushu region may be caused by the frequent volcanic eruptions in these three years. Ash from several volcanoes causes the transport of large fluxes of elements such as $\mathrm{P}$ and $\mathrm{Al}$, volatiles, nutrients, and metals. ${ }^{55}$ Volcanic ash coincident with heavy rainfall was likely deposited in the river basin, leading to the increase of $\mathrm{TP}$ concentration in the Honmyou River.

The mean values of $\mathrm{pH}$ in most rivers of Hokkaido, Hokuriku and Chugoku regions are around 7.2. Abashiri River in Hokkaido has a slightly higer value at 7.94 due to the pollution from livestock, urban wastewater and agriculture land. ${ }^{56}$ The rivers in Kanto and Kinki regions show a slightly higher mean value than other regions. The highest average value of $\mathrm{pH}$ is found at the 
Ashida River because of the urbanization in the upper reach of the Ashida River ${ }^{57}$ and the lack of wastewater treatment. Most rivers in Hokkaido region show increasing trends in $\mathrm{pH}$ value (Fig. 8). However, the mean value in Hokkaido is still small. Significant increasing trends were also found in the rivers around the Ariake Sea bay.

\subsection{Overall trend of water quality in Japan}

For the overall trend of the 98 water quality observation stations, the histogram for BOD, COD, DO, TN and TP is shown in Fig. 9. The left side of the dotted line shows the negative trend value and the right side of the dotted line shows the positive trend value. In Fig. 9, most water quality stations show BOD, COD, TN, and TP values with decreasing trends, with BOD showing the highest number of water quality stations with decreasing trends. The number of the stations measuring the increasing trends in DO is high. As can be seen from Fig.4 and Fig.3, the mean value of COD is a little higher than BOD.

On the whole, water quality in Japanese rivers improved dramatically over the time period investigated, but there are still several problems in some places, especially Hokkaido, Kanto, Kinki and Kyushu regions. Eutrophication associated with the effects of TN and TP are usually driven by land use, livestock grazing and human populations which can cause nutrient loading to surface waters. ${ }^{58}$ Major water quality improvements in Japan were achieved as a result of the management policies enacted in the 1970s. Elevated concentrations of TP and TN in Tokyo bay and Osaka bay are shown in Fig.6 and Fig.7 which are likely the results of high population densities in these two areas. ${ }^{47}$

\subsection{Spatial and temporal analysis of BOD, COD, DO, TN, TP and pH}

The following figures show the spatial analysis of the 98 water quality stations. As examples, the annual water quality data from 1992, 1995, 2000 and 2005 in which the dataset is complete were chosen to illustrate the spatial trends about every 5 years. In these figures, the four different color represented the concentration of 1992, 1995, 2000 and 2005. The main factor for the high values in some specific stations were illustrated in the red rectangles.

The two biggest peak values shown in Fig.10 reflect 1992 and 1995 BOD concentration at St.55 and St.58. However, the concentration in St.55 decreases by half after 1997 and is stable from 1998 to 2005, and the trend in St.58 decreases by $10 \mathrm{mg} / \mathrm{l}$ after 1993 and remains stable from 1995 to 2005. The Yamato River (St.55) has been identified as one of the lowest water quality rivers in Japan in these years because of the large annual average BOD concentration. ${ }^{59,60}$ The Ibo River (St.58) in Hyogo Prefecture flowing into the Seto Inland Sea also had a poor record: it was designated as the 3rd- to 5th-worst river in Japan in terms of water quality as a result of domestic wastewater discharge as well as discharge from local industries such as leather production. ${ }^{61}$ There are three obvious increasing trends in St.8 and St.10 in Hokkaido with $\mathrm{Z}$ test scores of 2.82 and 2.15 respectively, and St.49 in Chubu with a Z test result of 2.27 (Fig.8). The largest decreasing trends were shown in St.80 and St.91 in Kyushu. In St.80, there 
are two extreme high values in 1993 and 1994 which are likely caused by the volcanic eruptions during those years.

Fig.11 shows the increasing trend of COD concentration at St. 8 with a $Z$ test result of 1.81 . The results for St.31 and St. 43 had decreasing trends with $Z$ test results of -3.42 and -3.41 . The increasing trends with $\mathrm{Z}$ test values of 2.09 and 3.71 forSt.68 and St.74 are shown. At St.70, high concentrations of COD were seen in 1995 which may be attributed to the effect from urbanization in the upper reach of the Ashida River. ${ }^{57}$ The trends for COD concentration in St.80 and St.91 of Kyushu show the same decreasing trend as for BOD concentration.

Increasing trends are shown for all stations of Tohoku, Hokuriku and Shikoku regions (St.13St.23, St.32-St.41 and St.73-St.77) in Fig.12. Hokkaido has the highest average DO concentrations (St.1-St.12) and Kyushu region (St.78-St.98) has the lowest concentrations. In Fig.12, a decreasing trend of DO concentration is seen in St.7 of Hokkaido region with a Z test result of -3.02. St.27 (Arakawa River) and St.29 (Tsurumi River) show low concentrations of DO which may be a consequence of industrial activities as well as urbanization in the region. ${ }^{62,63}$ There is a decreasing trend in St.31 of Kanto region. Fig.12 also shows the decreasing trends in St.53 and St.63 with Z test results of -2.15 and -2.53 , respectively. At St.90 and St.91 of Oyodo River, there are low DO concentrations which likely result from municipal wastewater in the area. $^{64}$

Fig.13 shows St.6 in Hokkaido region with the highest increasing trend of TN concentration and a $\mathrm{Z}$ test result of 2.14. The trend for St.17, shows an increasing trend in Fig. 13 with a $\mathrm{Z}$ test result of 1.65. There is a highly decreasing trend in St.39 which is presented with a Z test result of -3.35. In St.80, there is a peak in TN concentration in 1992, and it had the highest decreasing trend with a $Z$ test value of -3.72 . The trend from St.91 also had a highly decreasing trend with a $\mathrm{Z}$ test score of -3.23. Fig.13 also shows increasing trends in St.68 and St.71 with Z results of 2.09 and 1.87 , respectively.

The trends for TP concentration at St.6, St.7 and St.8 of Hokkaido region show increasing trends, and St.8 had a clear increasing trend with a $\mathrm{Z}$ test result of 1.78 (Fig.14). St.26 also shows an increasing trend in TP concentration with a $\mathrm{Z}$ test result of 2.42. Fig.14 shows St.40 which had the highest decreasing trend with a $Z$ test result of -4.44 . The middle part of Fig.14 shows St.45 and St.46, both of which had increasing tends with $\mathrm{Z}$ test results of 1.43 and 2.43, respectively. St.90 showed the highest recorded values of TP in 1992 and 1995 with a decreasing trend indicated by $\mathrm{Z}$ test value of -3.18 .

Fig.15 shows the highest pH value in 1992, 1995, 2000 and 2005 at St.70 which is due to upstream urbanization. St. 9 also showed high $\mathrm{pH}$ values in 1992 and 2005 (pH=8.2) which may be caused by livestock, agriculture and urban wastewater. In Fig.10, Fig.11, Fig.13 and Fig.14, the spatial trends of BOD, COD, TN and TP are also analyzed by the Mann Kendall test. BOD trends in Hokkaido show that 7 river water quality stations measured increasing concentrations, but the COD trends in Hokkaido show only one water quality station with an increasing trend. With respect to DO trends in Hokkaido, most of the water quality stations measured increasing concentrations. However, there are clear increasing trends in recent years in both TN and TP at some stations in Hokkaido. 


\subsection{Implication for environmental monitoring and management}

\subsubsection{Necessity of online monitoring}

Significant advances in technologies for monitoring river water quality (and therefore drinking water quality) are urgently needed to safeguard freshwater resources. Existing water quality monitoring data is complex and tends to be complicated by uncertainties resulting from weather conditions, air pollution and watershed characteristics. In order to decrease these uncertainties and maximize public health protection in real time, there exists a need for real-time water quality monitoring systems. As this paper has shown, nature disasters happen suddenly in certain areas (especially in Kyushu, Chubu and Hokuriku) making real-time monitoring necessary. Early warning systems (EWS) are generally integrated systems consisting of monitoring instruments with an ability to analyze and interpret results in real time. ${ }^{65}$ The goal of implementing an EWS is to identify low-probability/high-impact contamination events in sufficient time to alert and safeguard the public. An EWS based on real time monitoring of river water quality could provide a fast and accurate means to distinguish between normal variations in water quality, contamination events, radioactive material, as well as nature disasters.

The spatiotemporal trend analysis presented in this study provides river water quality data at a national scale and offers a better understanding of current conditions in Japanese rivers. Stations with increasing trends and high average concentrations of deleterious river water quality parameters are easy to identify using the data presented here. Although we speculate about the causes of the increasing trends and high concentration at some stations, the cause of several unusual water quality conditions remain unknown.

\subsubsection{Environmental management for improving water quality}

Findings in this study show that the improvements seen in recent decades in Japanese river water quality are highly dependent on improved wastewater treatment and other water quality improvement efforts promoted under government initiative. In Japan, the Law concerning Special Measures for Preservation of Lake Water Quality was amended to strengthen non-point source control measures and is one of the major drivers of water quality improvement. ${ }^{66}$

The average BOD and COD concentration in river water of Japan has dropped from $3 \mathrm{mg} / \mathrm{l}$ in 1979 to $1.6 \mathrm{mg} / \mathrm{l}$ in 2003. ${ }^{67}$ Compliance rates with Environmental Quality Standards (EQS) for BOD and COD in overall public water areas have gradually risen over time (except for 1994 and 2005 when compliance rates for rivers fell due to the effects of drought), reaching 86.3\% in 2006 (the highest record ever). ${ }^{67}$ The main causes are considered to be improvements in water treatment in major factories and dissemination of sewage systems and "Joukasou" (a Japanese system for household wastewater treatment). The increase of BOD and COD in some areas such as Hokkaido may be explained by anthropogenic effects. Other studies conducted in Japan attribute changes in water quality to land use or effects of domestic waste (e.g. Tabayashi and Yamamuro $^{68}$ ). Environmental management must focus on reducing key pollution sources, including emissions from point sources through discharge limits or other approaches. However, this requires careful analysis based on land use change, urban population density, urbanization rates, etc. This study also demonstrates that extreme hydro-geological disaster events have a 
great impact on river water quality. Further efforts will be necessary to address uncertainties related to the occurrence of such disasters as well as appropriate measures to mitigate their effects.

Lessons learned from the water quality improvement in Japan inform the need to couple land use change and domestic waste management with appropriate legal measures as well as cooperation between citizens and policy-makers to commit to those decisions.

\section{Conclusion}

This study presents the results of spatial and temporal trend analyses using the Mann-Kendall test to generate useful water quality information about Japanese rivers. Overall, trends show improvement in Japanese river water quality over the last 14 years (1992-2005). The reason for increasing water quality in most Japanese rivers is likely related to proactive policies enacted by the Japanese government. Decreasing water quality in the rivers of Hokkaido was identified. The COD trend of most rivers in Japan increased more significantly than BOD. TP increased more than TN in the main-land of Japan. This paper provides a comprehensive discussion of the trends in water quality indicators in Japanese rivers. Some extreme hydro-geological disaster events were also found to have had a great impact on the spatiotemporal trend and average conditions of river water quality. The unusual water quality conditions are linked with the events or disasters but further study is necessary to clearly identify causes of poor water quality. Although this study generates the results of spatiotemporal trend of recent water quality condition in Japanese rivers, our data set was limited to 14 years. More data would generate more robust results and reinforce the accuracy of the trend analysis. The links between land use, human activities, fertilizer, industrial and wastewater treatment plant effluent, the effects of dams and water quality trends need to be investigated more closely. Cluster analysis of these variables and water quality trend analysis is also suggested for future work. It is the hope of the authors that the analysis presented here will support the efforts of policy makers in the future. The necessity of online monitoring and environmental management for improving water quality are suggested as further research.

\section{Acknowledgment}

This study was supported by the Kyoto University Global COE program on "Human Security Engineering for Asian Megacities" and "Sustainability/Survivability Science for a Resilient Society Adaptable to Extreme Weather Conditions", the Obayashi Foundation and the JSPS Grant-in-Aid for Young Scientists (B). The authors are grateful for their support. We also thank the reviewers, Mr. Pedro Luiz Borges Chaffe and Mr. Apip for providing great comments on this paper. 


\section{References}

1 M. Kido, Yustiawati, M. S. Syawal, Sulastri, T. Hosokawa, S. Tanaka, T. Saito, T. Iwakuma, M. Kurasaki, Environ Monit Assess, 2009, 156, pp.317-329.

2 L. Claessens, C. Hopkinson, E. Rastetter and J. Vallino, Water Resour. Res., 2006, 42, W03426.

3 H. J. Chang, Hydrol. Process., 2007, 21, 211-222.

4 T. R. Oke, published in the USA by Methuen, New York, 1987, 2 edition, ch. 3, pp. 98-106.

5 A. Baker, Hydrol. Proc., 2003, 17 (12), 2499-2501.

6 I. Delpla, A.V. Jung, E. Baures, M. Clement and O. Thomas, Environment International, 2009, $35,1225-1233$.

7 R. B. Deano, M. T. Rodriguez and A.J. F. Espinosa, Journal of Hydrology, 2008, 361, 227239.

8 P. Simeonov, J. Einax, I. Stanimirova, J. Kraft, Analytical and Bioanalytical Chemistry, 2002, 374 (5), 898-905.

9 J. J. Berzas, L. F. Garcı'a, R. C. Rodrı'guez and P. J. Martı'n-Alvarez, Water Research, 2000, 34, 3161-3170.

10 B. He, S. Kanae, T. Oki, Y. Hirabayashi, Y. Yamashiki and K. Takara, Water Research, 2011, 45(8), 2573-2586.

11 T. Nobukawa, S. Sanukida, Water Research, 2002, 36, 989-995.

12 S. Shrestha and F. Kazama, Environmental Modelling \& Software, 2007, 22, 464-475.

13 M. Yamamuro and Y. Kanai, Chemical Geology, 2005, 218, 51- 61.

14 T. Nakano, I. Tayasu, Y. Yamada, T. Hosono, A. Igeta, F. Hyodo, A. Ando, Y. Saitoh, T. Tanaka, E. Wada, S. Yachi, Science of the Total Environment, 2008, 389, 132 - 148.

15 T. Yoshimura, I. Kudo, M. Yanada, K. Matsunaga, Limnology, 2000, 1, 63-68.

16 K. P. Woli, T. Nagumo, R. Hatano, Nutrient Cycling in Agroecosystems, 2002, 63, 175-184.

17 J. Shindo, K. Okamoto and H. Kawashima, Ecological Modelling, 2003, 169, 197-212.

18 J. Shindo, K. Okamoto and H. Kawashima, Ecological Modelling, 2006, 193(3-4), 703-720.

19 B. He, K. Oki, Y. Wang and T. Oki, Water Science and Technology, 2009a, 60(8), 2009-2015.

20 B. He, T. Oki, S. Kanae, G. Mouri, K. Kodama, D. Komori and S. Seto, Ecological Modelling, 2009b, 220, 2325-2334. 
21 B. He, T. Oki, F. Sun, D. Komori, S. Kanae, Y. Wang, H. Kim and D. Yamazaki, Journal of Environment Management, 2010, 92(1), 172-177.

22 D. R. Helsel and R. M. Hirsch, Studies in Environmental Science, Vol. 49, Elsevier, 1992.

23 M. B. Paul and C. B. Linfield, Statistics for Environmental Engineers. Lewis publishers, 2002.

24 H. J. Chang, Water Air Soil Pollut., 2005, 161, 267-284.

25 H. W. Lee, K. J. Bhan and S. S. Park, Ecological Informatics, 2010, 5, 281-292.

26 R. C. Ferrier, A. C. Edwards, D. Hirst, I. G. Littlewood, C. D. Watts and R. Morris, The Science of the Total Environment, 2001, 265, 327-342.

27 A. Loukas, Desalination, 2010, 250, 266-273.

28 H. M. Bu, X. Tan, S. Y. Li and Q. F. Zhang, Ecotoxicology and Environmental Safety, 2010, $73,907-913$.

29 S. J. Interlandi and C. S. Crockett, Water Research, 2003, 37 (8), 1737-1748.

30 G. Hanrahan, M. Gledhill, W. A. House and P. J. Worsfold, Water Res., 2003, 37 (15), 35793589.

31 F. Yenilmez, F. Keskin and A. Aksoy, Physics and Chemistry of the Earth, 2010, doi:10.1016/j.pce.2010.05.005, 135-140.

32 S. Pla, A. M. Paterson, J. P. Smol, B. J. Clark and R. Ingram, J. Great Lakes Res. 2005, 31, 253-266.

33 K. H. Nicholls, J. H. Gordon, S. J. Standke and L. Nakamoto, J. Great Lakes Res., 2001, 27(4), 402-422.

34 A. D. Steinman, M. Ogdahl, R. Rediske, C. R. Ruetz III, B. A. Biddanda and L. Nemeth, J. Great Lakes Res., 2008, 34, 169-188.

35 X.L. Wang, J.Y. Han, L.G. Xu and Q. Zhang, Environmental Pollution, 2010, 158, 15131520.

36 B. Arheimer and R. Liden, J. Hydrol. 2000, 227, 140-159.

37 I. Donohue, M. L. McGarrigle and P. Mills, Water Res., 2006, 40 (1), 91-98.

38 Ministry of Land, Infrastructure, Transport and Tourism (MLIT), http://www.mlit.go.jp/index_e.html.

39 R. Revelli and L. Ridolfi, Advances in Water Resources, 2004, 27(9), 943-952.

40 K. H. Lee, T. Ishikaw, S. J. McNiven, Y. Nomura, A. Hiratsuka, S. Sasaki, Y. Arikawa and I. Karube, Analytica Chimica Acta, 1999, 398, 161-171.

41 Y.S. Yu, S. Zou and D. Whittemore, Journal of Hydrology, 1993, 150, 61-80. 
42 K. H. Hamed and A. R. Rao, Journal of Hydrology, 1998, 204, 182-196.

43 K.H. Xu, J. D. Milliman and H. Xu, Global and Planetary Change, 2010, doi:10.1016/j. gloplacha.2010.07.002, 219-232.

44 R. O. Gilbert, Pacific Northwest Laboratory0-442-23050-8, 1987.

45 K. Tani, Papers and Proceedings of the Geographic Information Systems Association, 2002, 11, 215-220.

46 S. Hara, GIS in Humanities and Social Sciences, 2009, 1-16.

47 K. Roy, Journal of Developments in Sustainable Agriculture, 2007, 2, 27-34

48 T. Tokui, Scientific Reports of the Hokkaido Salmon Hatchery, 1966, 20, 83-89. (In Japanese with English summary).

49 Tokapuchi, River Improvement and Management Project: Tokachi River Basin, Hokkaido Regional Development Bureau, River Improvement and Management Division, Obihiro Development and Construction Department, Ministry of Land, Infrastructure, Transport and Tourism (MLIT), 2002. Available at http://www.ob.hkd.mlit.go.jp/.

50 K. Kumazawa, Jap. J. Soil Sci. Plant Nutr., 1999, 70, 207-213 (in Japanese).

51 S. Mishima, Nutrient Cycling in Agroecosystems, 2002, 63, 151-163.

52 Hokkaido Future Creation Plan (HFCP), http://www.pref.hokkaido.lg.jp/ss/ksk/grp/11/ jigyoukeikakuhenkou.pdf, accessed July 1, 2011.

53 T. Nagumo and R. Hatano, Japanese Society of Soil Science and Plant Nutrition, Japan, 2001, 72(1), 41-48 (in Japanese).

54 N. C. Hansen, S. C. Gupta and J. F. Moncrief, Soil \& Tillage Research, 2000, 57, 93-100.

55 M. T. Jones and S. R. Gislason, Geochimica et Cosmochimica Acta, 2008, 72, 3661-3680.

56 Y. Ishikawa, O. Saitoh, M. Kaneko, M. Kobayashi and Y. Kiuchi, Report of Hokkaido Institute of Environmental Sciences, 2002, 29, 46-52.

57 M. Ojima, M. Kobayashi, The memoirs of the Faculty of Engineering, Fukuyama University, 1998, 22(1), 17-30.

58 P. Johnes, B. Moss and G. Phillips, Freshwater Biology, 1996, 36, 451-473.

59 Y. Tsuzuki, M. Fujii, Y. Mochihara, K. Matsuda and M. Yoneda, Journal of Environmental Sciences, 2010, 22 (6), 892-897.

60 Y. Tsuzuki, M. Yoneda, Journal of Hydrology, 2011, 400, 465-476.

61 JRRN, World's WATERFRONT: in JAPAN, 2010, http://www.arr.net/jp/en/waterside/domestic/ water_quality _ restoration/1533.html, accessed July 1, 2011. 
62 World Water Assessment Programme (WWAP), UNESCO Pub. : Berghahn Books, 2003, Chapter 22, 481-489.

63 K. Yoshikawa, Restoration of Tsurumi River (Tokyo). Community and urban river restoration, Kanto, Japan River Restoration Network (JRRN), 2011. Available at http://www.arr.net/jp/en/waterside/domestic/docs/03-0009Eng.pdf.

64 A. Izumi, T. Kasuhide, S. Akio, K. Koichi, A. Yoshifumi and K. Kenichi, Annual Report of the Miyazaki Prefectural Institute for Public Health and Environment, 2004, 15, 89-93.

65 W. M. Grayman, R. M. Deininger and R. A. Males, AWWA Research Foundation Report, (Denver) , 2001.

66 Water Environment Partnership in Asia (WEPA), Outlook of Water Environmental Management Strategies in Asia, 2009. Available at http:// www.env.go.jp/en/.

67 Water Environment Partnership in Asia (WEPA), Results of the FY 2006 Water Quality Survey of Public Water Areas, 2006. Available at http://www.wepa-db.net/policies/state/japan.

68 Y. Tabayashi and M. Yamamuro, Wetlands Ecology and Management, 2009, 17(4), 409-415. 
Table 1. River names and water quality observation stations used in this study.

\begin{tabular}{|c|c|c|c|c|c|c|c|c|}
\hline ID & River Name & Water Quality Station & ID & River Name & Water Quality Station & ID & River Name & Water Quality Station \\
\hline St.1 & Teshio & Teshio-Ohashi & St.34 & Shinano & Heisei-Ohashi & St.67 & Takatsu & Takatsuno \\
\hline St.2 & Rumoi & Rumoibashi & St. 35 & Shinano & Watanabebashi & St.68 & Saba & Sabagawa-Ohashi \\
\hline St.3 & Ishikari & Ishikarikakobashi & St.36 & Seki & Naoetsubashi & St.69 & Oze & Yamatobashi \\
\hline St.4 & Shiribeshi. & Kabutonobashi & St.37 & Hime & Himegawa-Ohashi & St.70 & Ashida & Kominomibashi \\
\hline St.5 & Mukawa & Mukawabashi & St.38 & Kurobe & Shitakurobebashi & St.71 & Takahashi & Kasumibashi \\
\hline St.6 & Saru & Sarugawabashi & St.39 & Jyoganji & Imagawabashi & St.72 & Yoshii & Eianbashi \\
\hline St.7 & Tokachi & Aiushibashi & St.40 & Jinzu & Hagiurabashi & St.73 & Shigenobu & Deaibashi \\
\hline St. 8 & Kushiro & Shinkawabashi & St.41 & Oyabe & Kako(Oyabe) & St.74 & Watari & Shimoda \\
\hline St.9 & Abashiri & Abashiribashi & St.42 & Kano & Kurosebashi & St.75 & Monobe & Fukabuchi \\
\hline St.10 & Tokoro & Kamikawazoi & St.43 & Abe & Abegawabashi & St.76 & Doki & Marugamebashi \\
\hline St.11 & Yubetsu & Nakayubetsubashi & St.44 & $\mathrm{Oi}$ & Fujimibashi & St.77 & Yoshino & Ichibabashi \\
\hline St.12 & Shokotsu & Shokotsubashi & St.45 & Kiku & Kuniyasubashi & St.78 & Onga & Ashiya \\
\hline St.13 & Iwaki & Jyusan-Ohashi & St.46 & Tenryu & Kakezukabashi & St.79 & Matsura & Maizurubashi \\
\hline St.14 & Yoneshiro & Noshiro & St.47 & Kiso & Yokomakura & St. 80 & Honmyo & Shiranui \\
\hline St.15 & Omono & Osumonoshinbashi & St.48 & Kiso & Ise-Ohashi(Ibi R.) & St.81 & Rokkaku & Suminoebashi \\
\hline St.16 & Koyoshi & Honjo-Ohashi & St.49 & Kiso & Ise-Ohashi (Nagara R.) & St.82 & Chikugo & Sagayamebashi \\
\hline St. 17 & Mogami & Ryoubashi & St.50 & Suzuka & Ogurabashi & St.83 & Yabe & Urashimabashi \\
\hline St.18 & Aka & Shinkawabashi(Hamanaka) & St.51 & Mozu & Kumozubashi & St.84 & Kikuchi & Takase \\
\hline St.19 & Abukuma & Iwanuma & St.52 & Kushida & Kushidabashi & St.85 & Shira & Kojimabashi \\
\hline St.20 & Natori & Yuriage-Ohashi & St.53 & Shingu & Kumanogawakako & St.86 & Midori & Hirakibashi \\
\hline St.21 & Naruse & Ono & St.54 & Kino & Kinokawa-Ohashi & St. 87 & Midori & Omagari \\
\hline St.22 & Kitakami & Kadowaki & St.55 & Yamato & Orionobashi & St.88 & Sendai & Ogura \\
\hline St.23 & Mabechi & Ohashi & St.56 & Yodo & Denbo-Ohashi & St.89 & Kimotsuki & Dainiariakebashi \\
\hline St.24 & Kuji & Sakakibashi & St.57 & Kako & Aioibashi & St.90 & Oyodo & Odonobashi \\
\hline St.25 & Naka & Kaimonbashi & St.58 & Ibo & Honmachibashi & St.91 & Oyodo & Bandokorobashi \\
\hline St.26 & Tone & Choshi-Ohashi & St.59 & Kuzuryu & Fuseda & St.92 & Omaru & Miyatagawasuimon \\
\hline St.27 & Ara(Kanto) & Kasaibashi & St.60 & Kita & Takatsuka & St.93 & Banjyo & Banjyogawakako \\
\hline St.28 & Tama & Daishihashi & St.61 & Yura & Yuragawabashi & St.94 & Ono & Kaiharabashi \\
\hline St.29 & Tsurumi & Rinkoutsurumikawabashi & St.62 & Maruyama & Minato-Ohashi & St.95 & Ono & Ieshima \\
\hline St.30 & Sagami & Banyubashi & St.63 & Sendai & Gyotoku & St.96 & Oita & Benten-Ohashi \\
\hline St.31 & Fuji & Fujikawabashi & St.64 & Tenjin & Oda & St.97 & Yamakuni & Yamakunibashi \\
\hline St.32 & Ara & Asahibashikaryu & St.65 & Hino & Kuzumo & St.98 & Kase & Kubotabashi \\
\hline St.33 & Agano & Matsuhamabashi & St.66 & Kono & Kawahira & & & \\
\hline
\end{tabular}


Table 2 Distribution of sampling rivers and stations.

\begin{tabular}{lll}
\hline Regions Name & Amount of Sampling Rivers & Amount of Sampling Stations \\
\hline Hokkaido & 12 & 12 \\
Tohoku & 11 & 11 \\
Kanto & 8 & 8 \\
Hokuriku & 9 & 10 \\
Chubu & 9 & 11 \\
Kinki & 10 & 10 \\
Chugoku & 10 & 10 \\
Shikoku & 5 & 5 \\
Kyushu & 18 & 21 \\
\hline
\end{tabular}




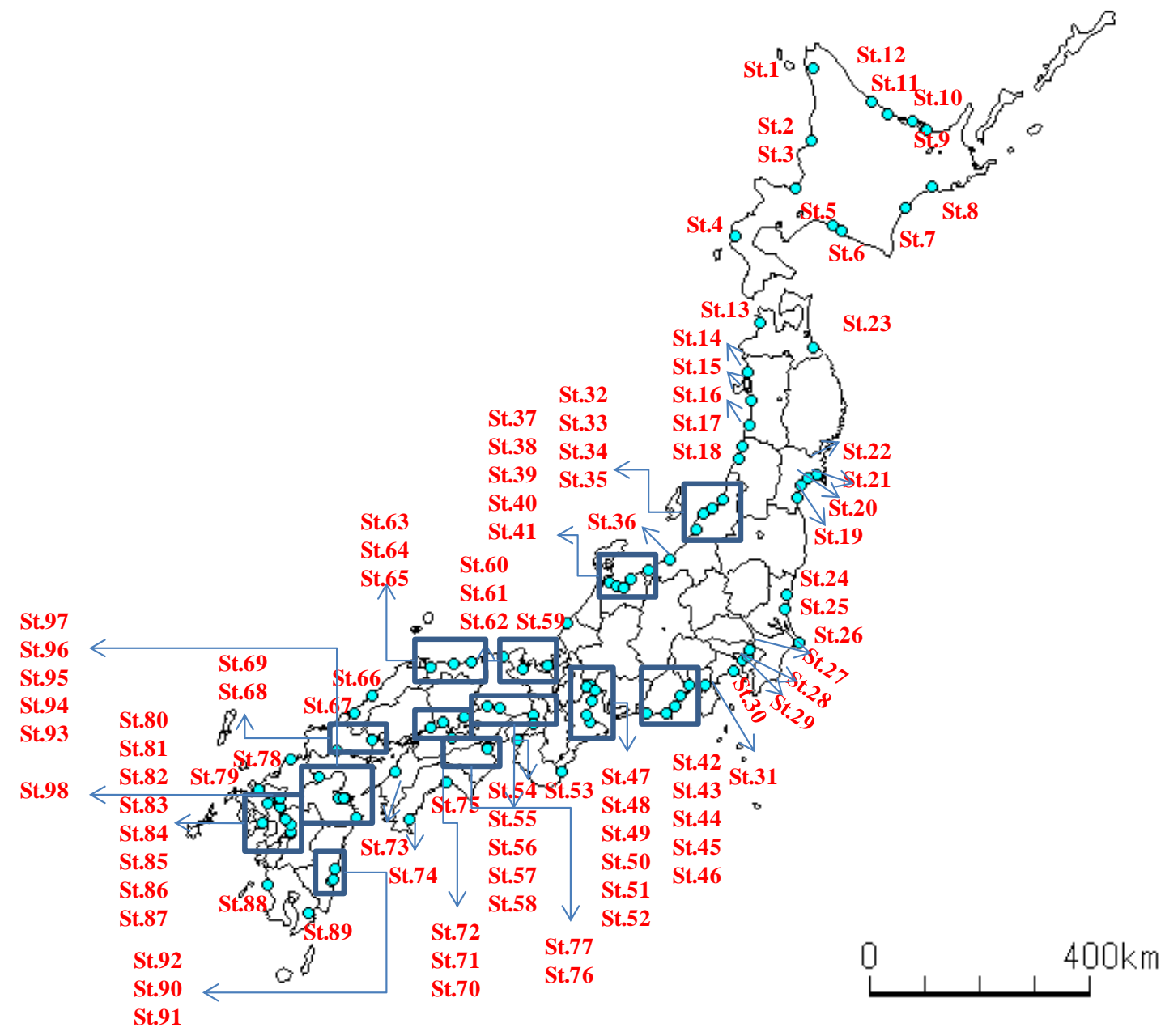

Fig.1 Location map of selected water quality observation stations. For each square, the order of station ID is demonstrated from up to down or from right to left. 


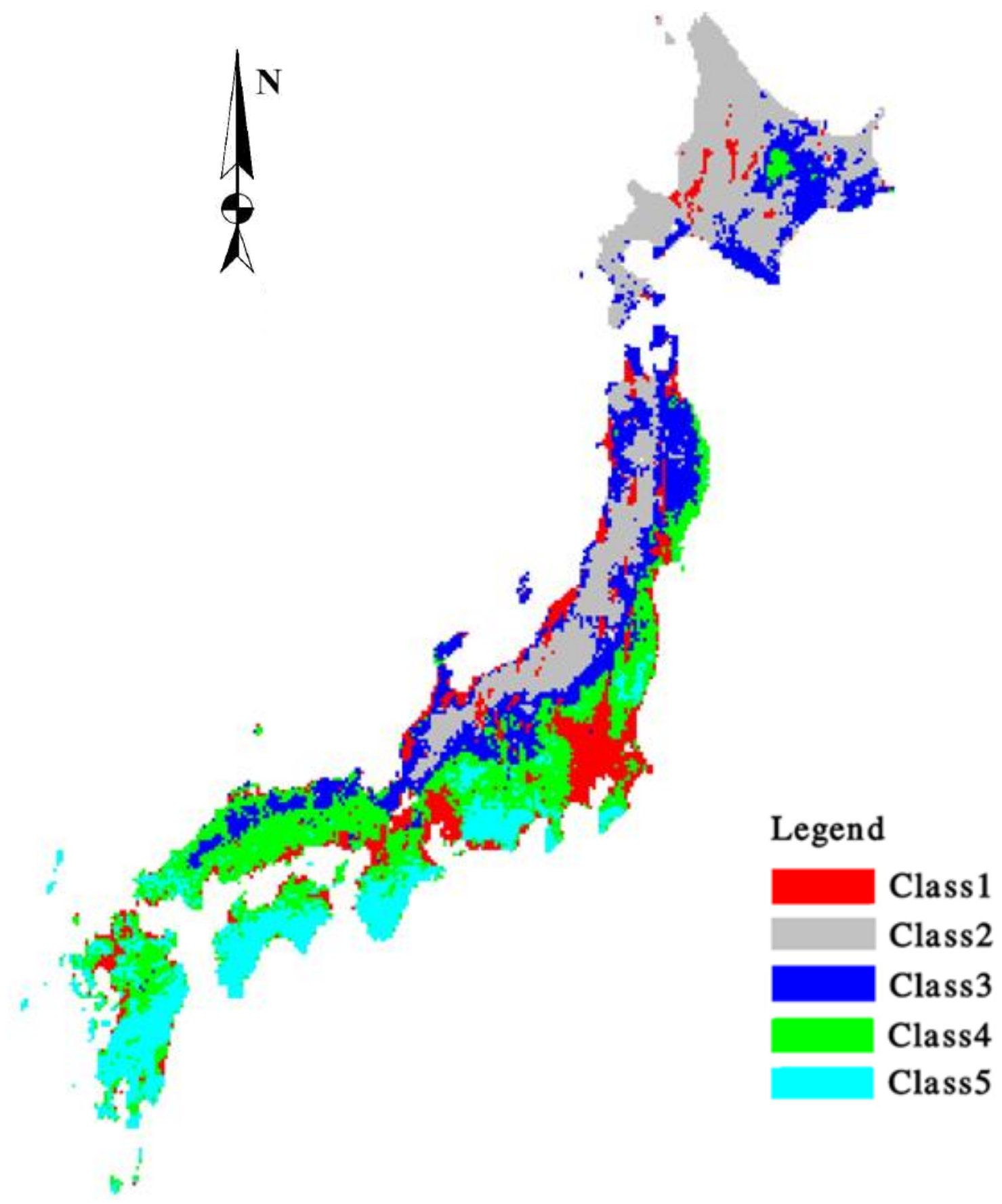

Fig.2 1996 Land use map in Japan (Modified from He et al., 2009a). Class 1 is Urban area, Class 2 is natural vegetation, Class 3 is secondary vegetation, Class 4 is Camellia japonica community type, Class5 is Plantation and field-weed communities. 


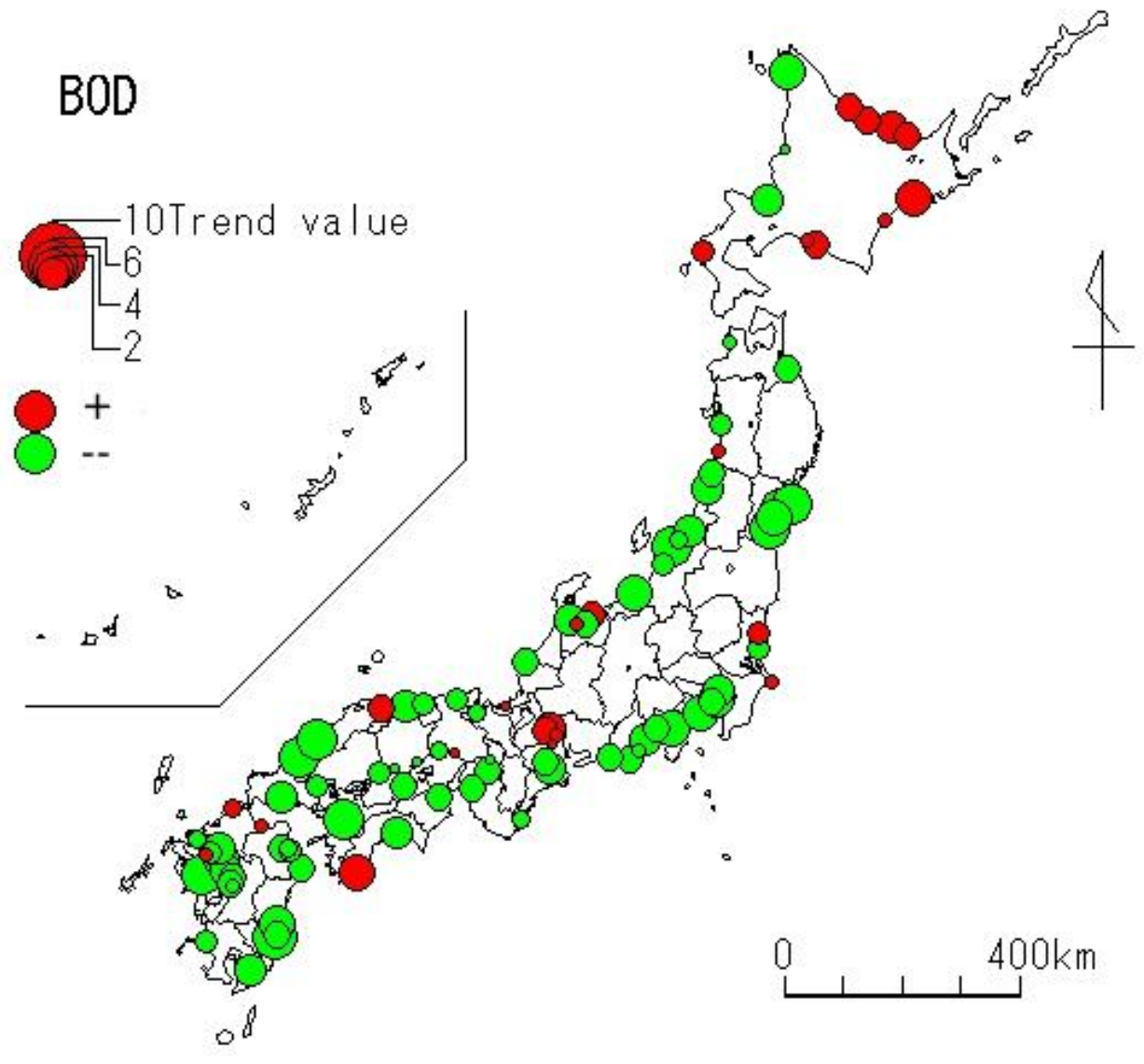

Fig. 3 BOD trend value of 98 observed stations (red color is positive, green color is negative.) 


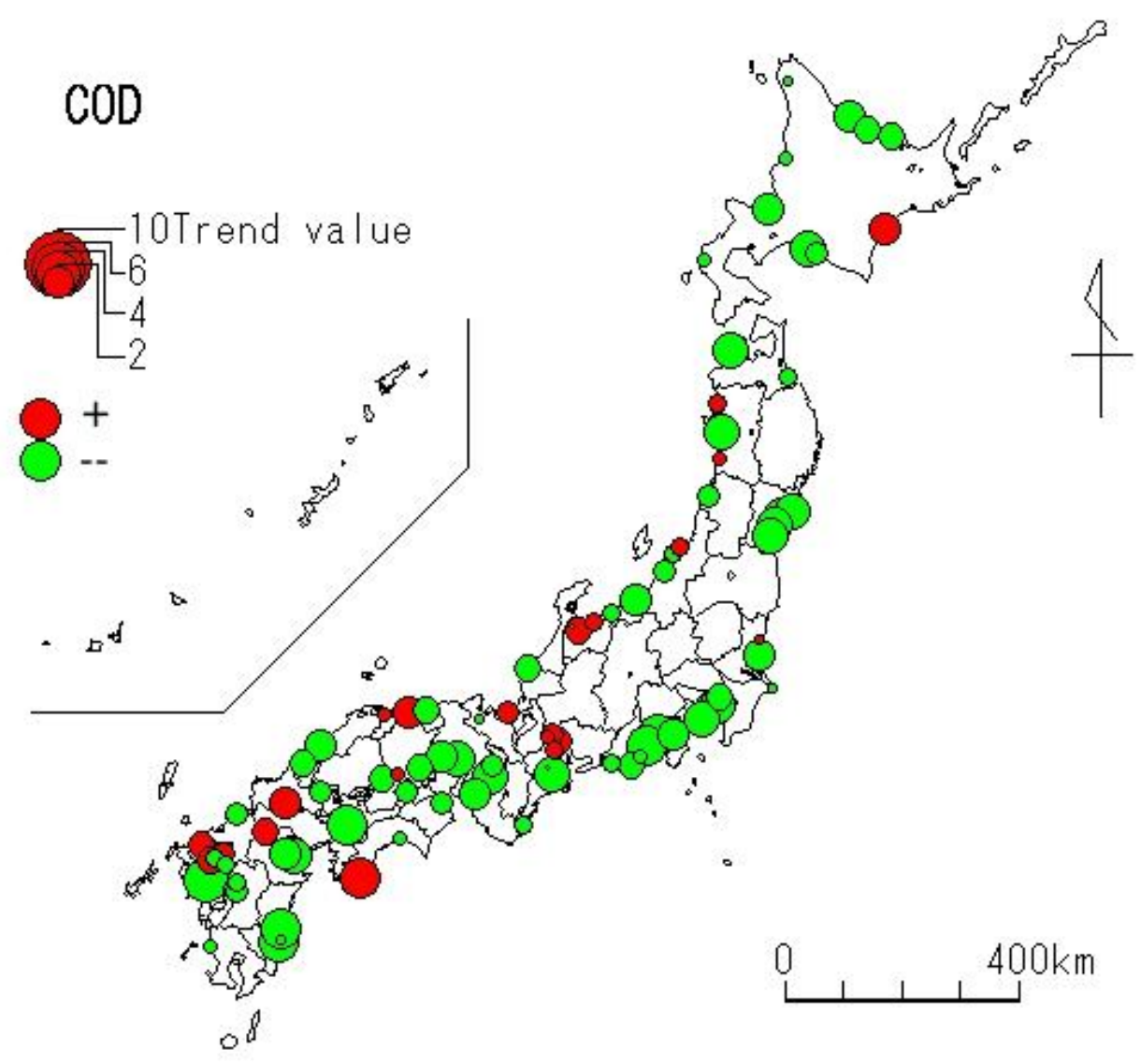

Fig.4 COD trend value of 98 observed stations (red color is positive, green color is negative.) 


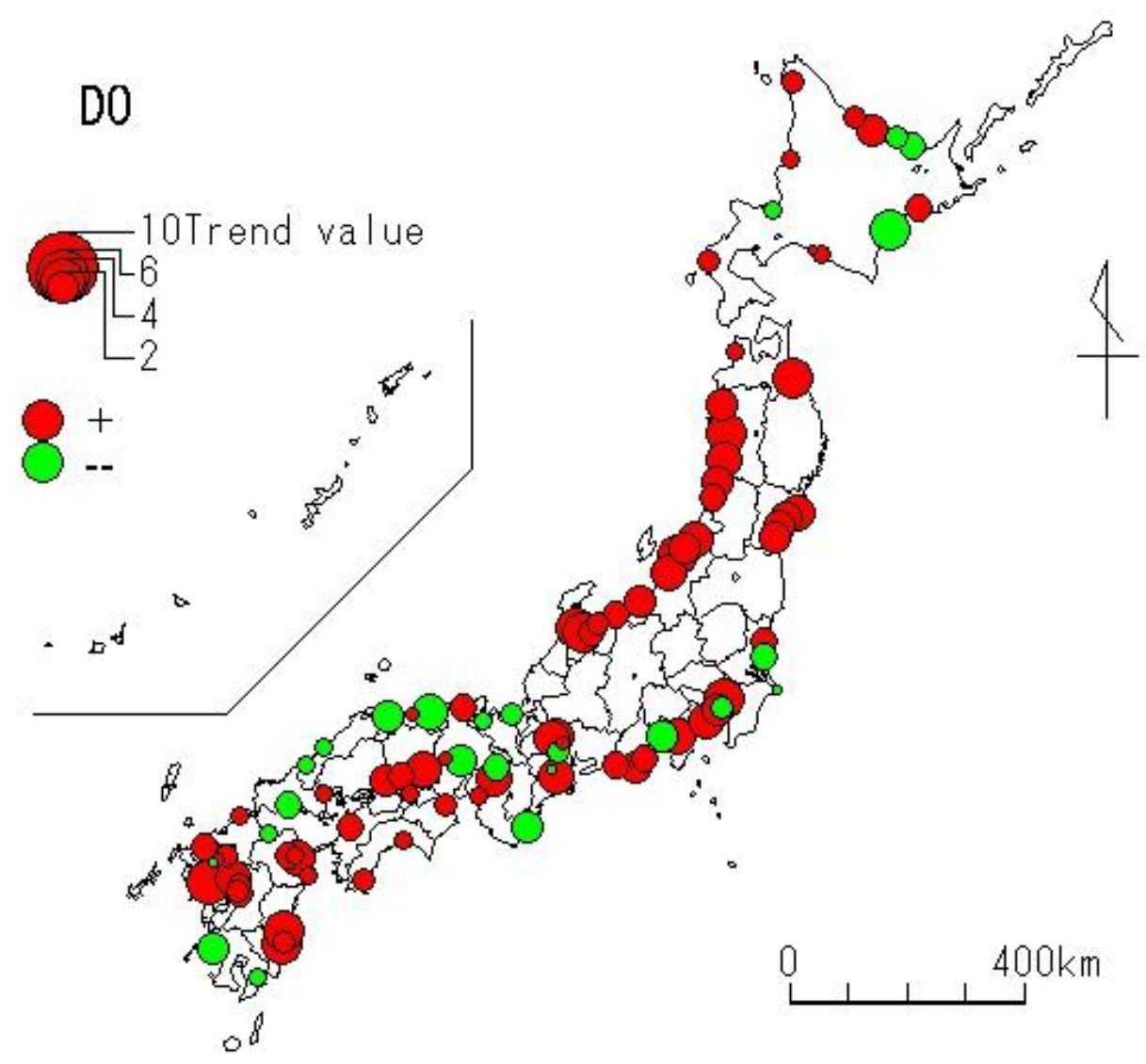

Fig.5 DO trend value of 98 observed stations (red color is positive, green color is negative.) 


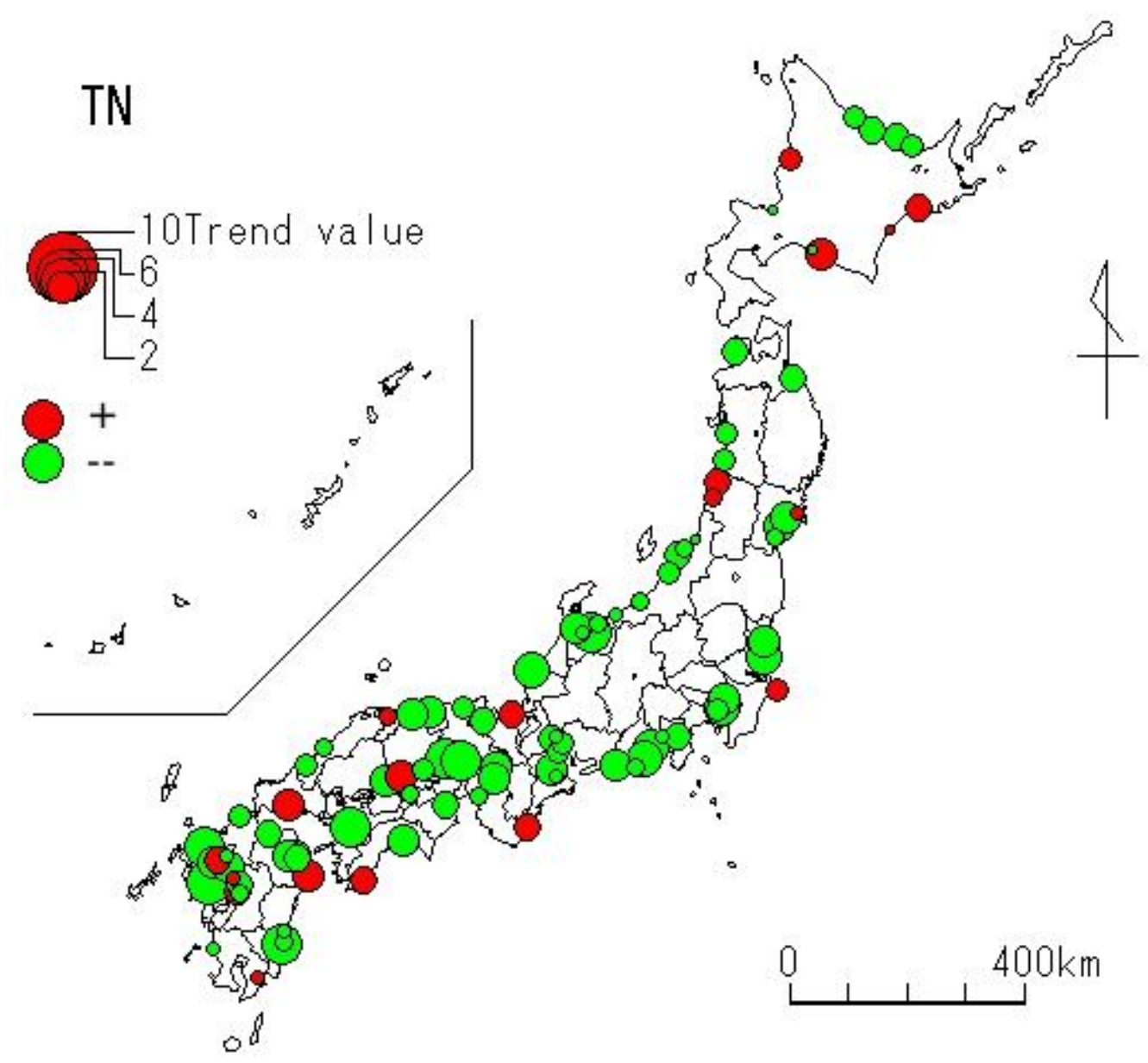

Fig.6 TN trend value of 98 observed stations (red color is positive, green color is negative.) 


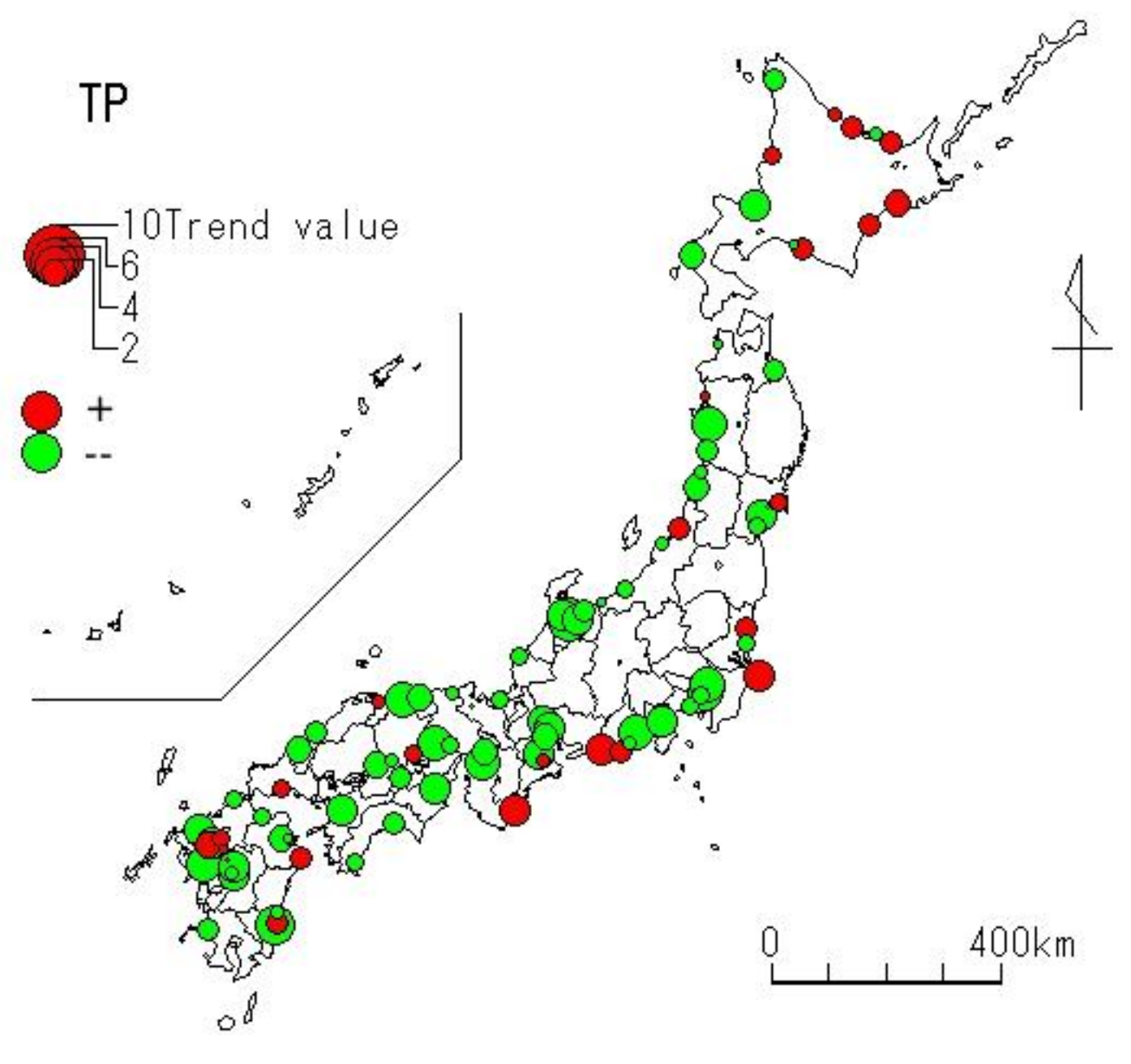

Fig.7 TP trend value of 98 observed stations (red color is positive, green color is negative.) 


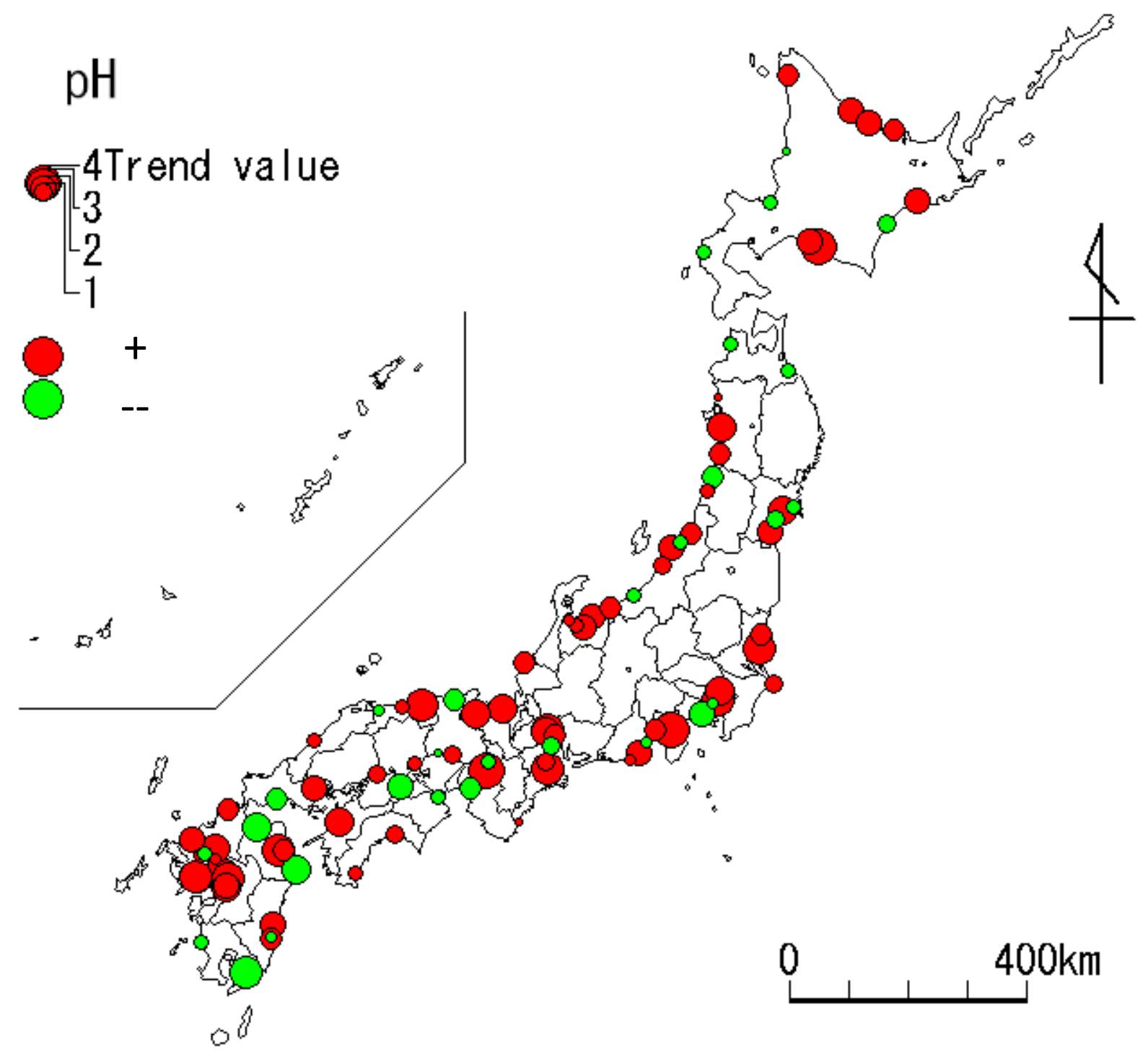

Fig.8 PH trend value of 98 observed stations (red color is positive, green color is negative.) 


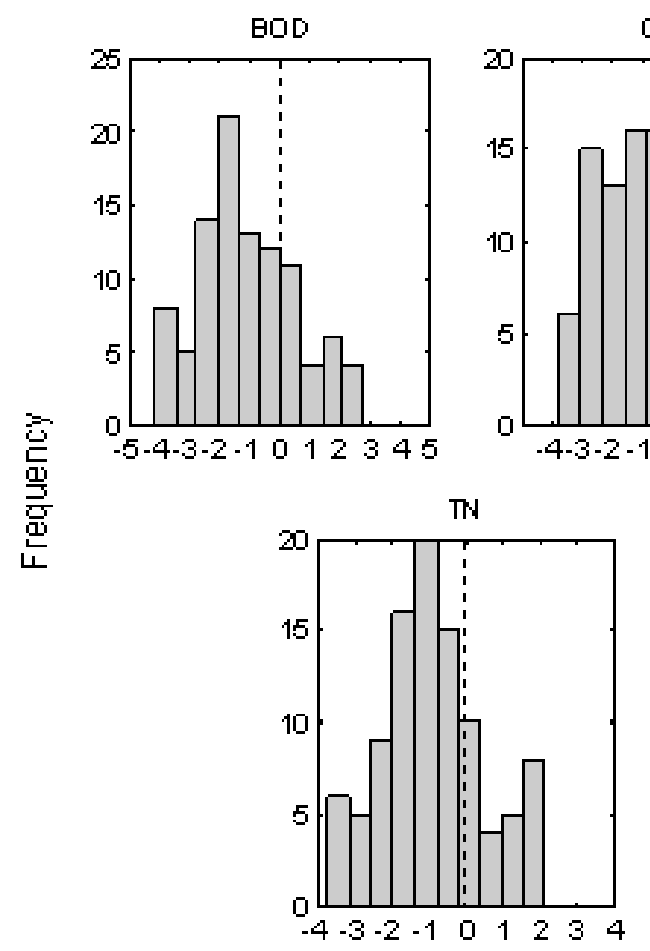

$\operatorname{COD}$
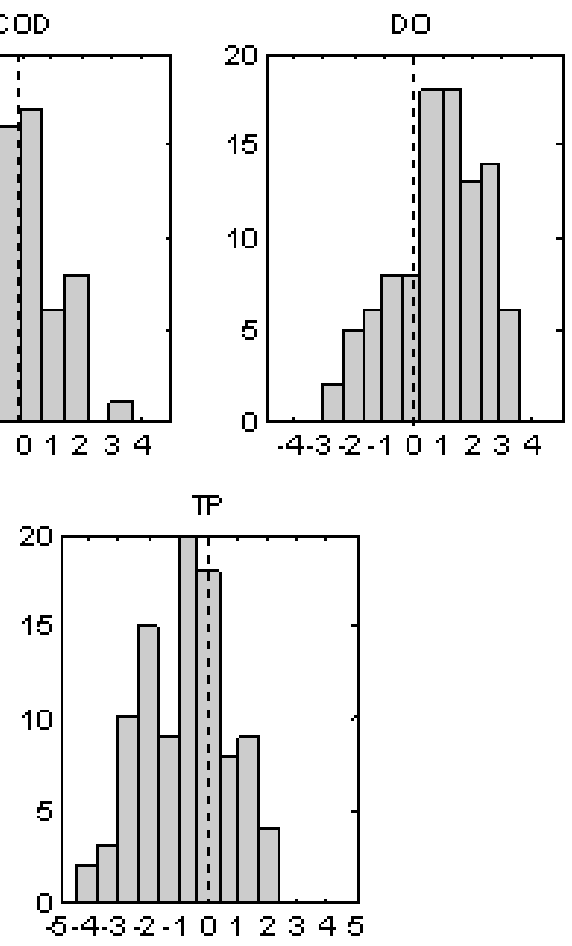

Trend Value

Fig.9 Histogram for the trend values calculated in the 98 water quality observation stations. BOD is Biochemical oxygen demand, COD is chemical oxygen demand, DO is dissolved oxygen, TN is total nitrogen, TP is total phosphorus. The dotted line indicates the value 0 (no trend). 


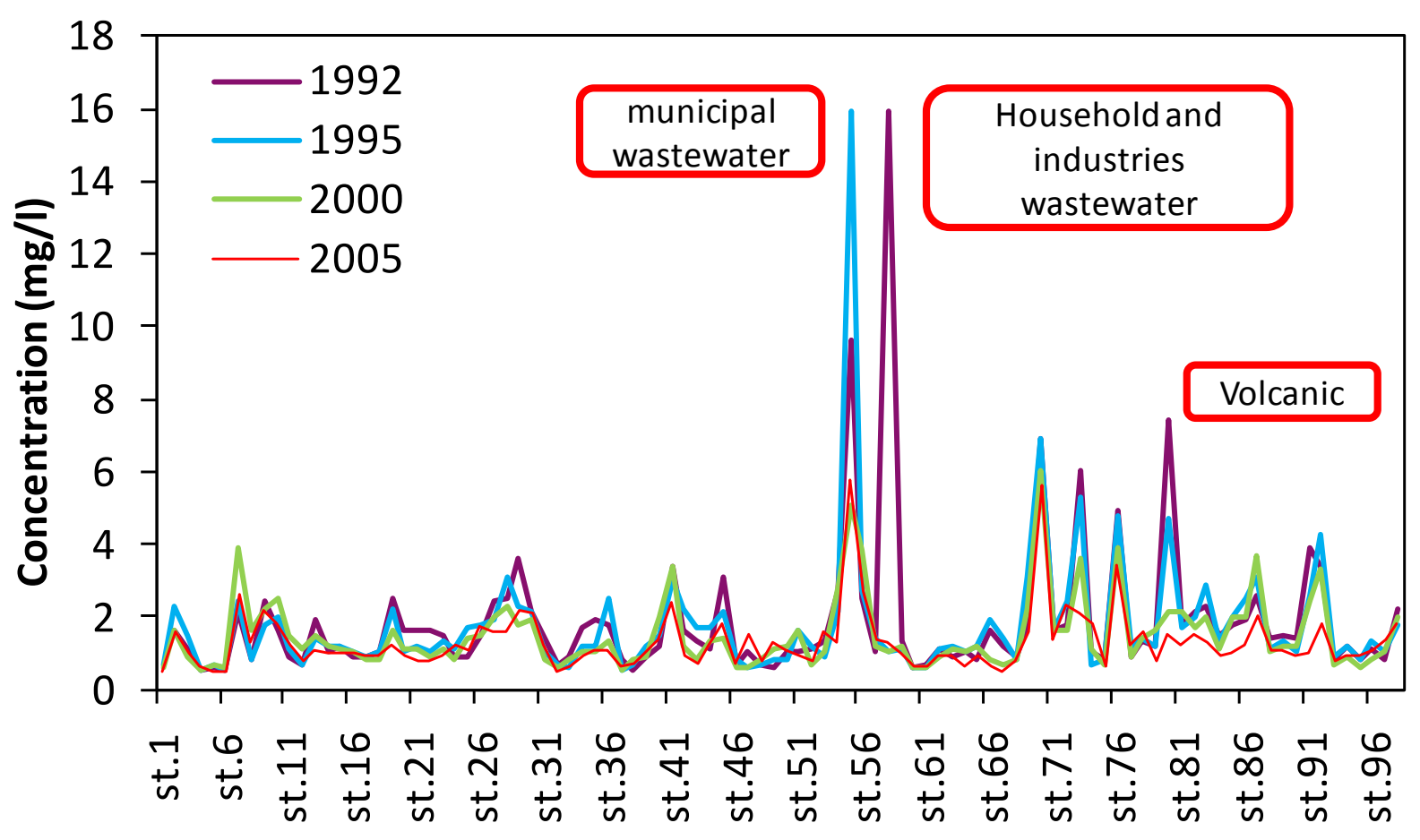

Fig.10 Spatial comparison of BOD concentration. 


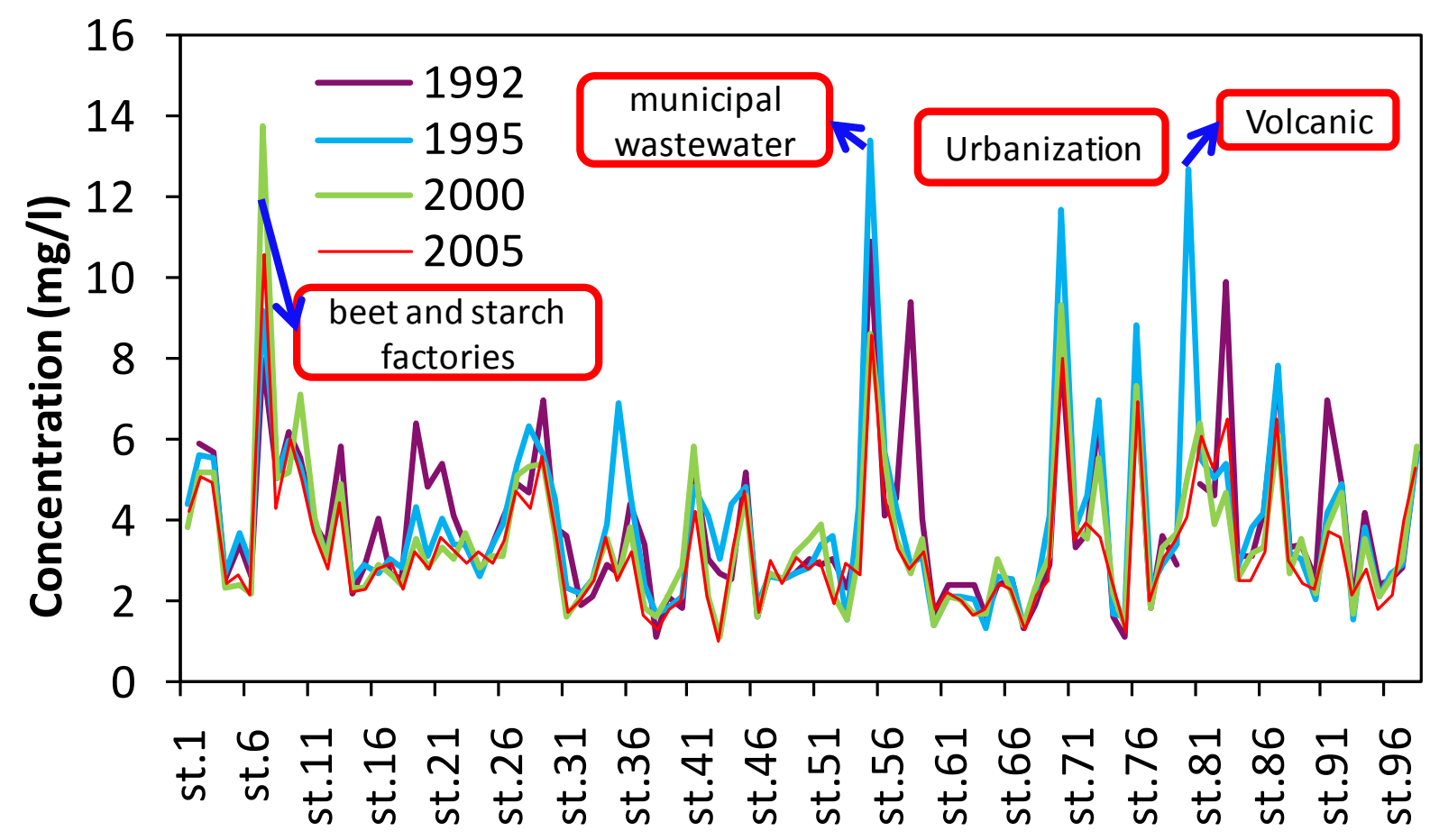

Fig.11Spatial comparison of COD concentration. 


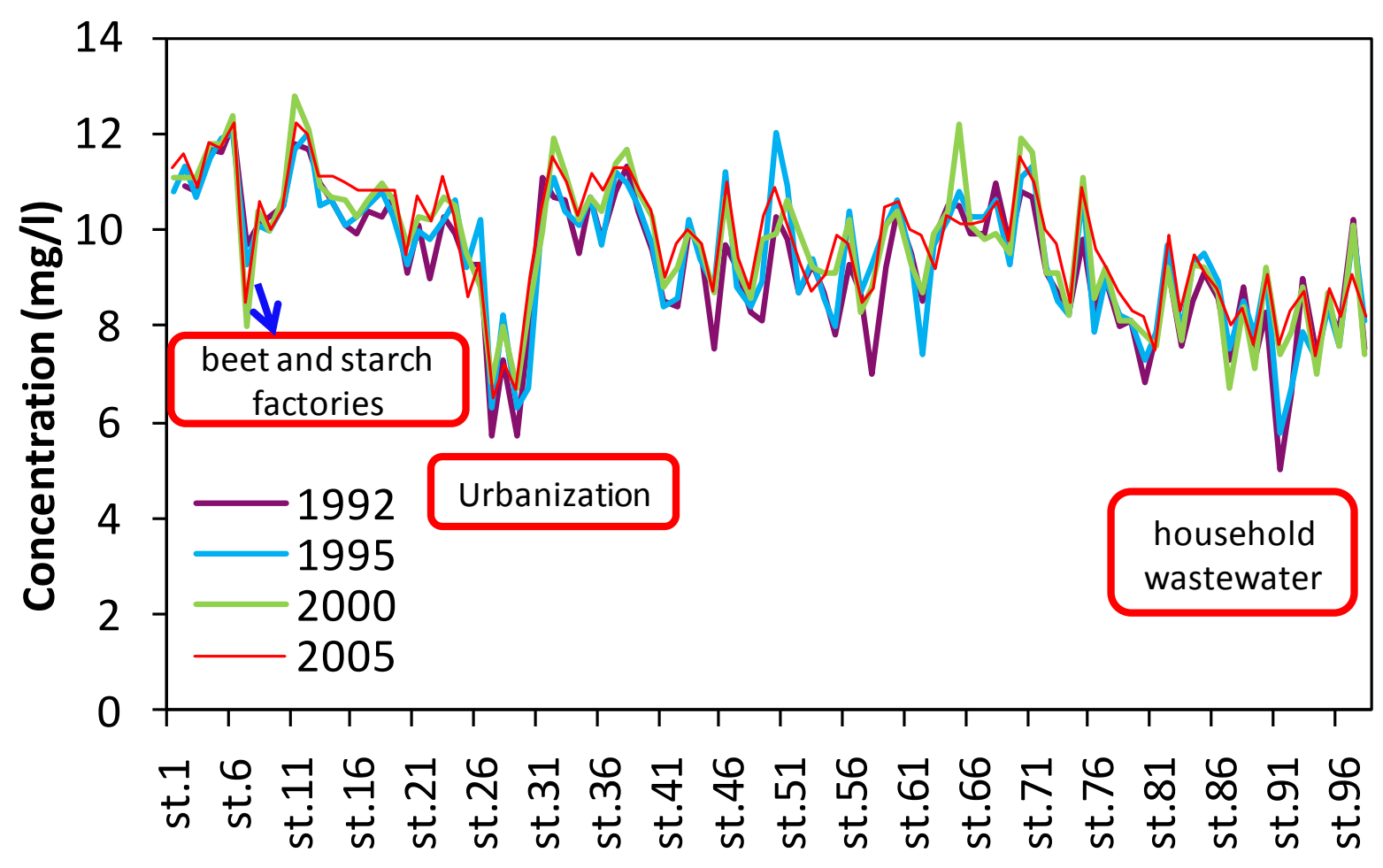

Fig.12 Spatial comparison of DO concentration. 


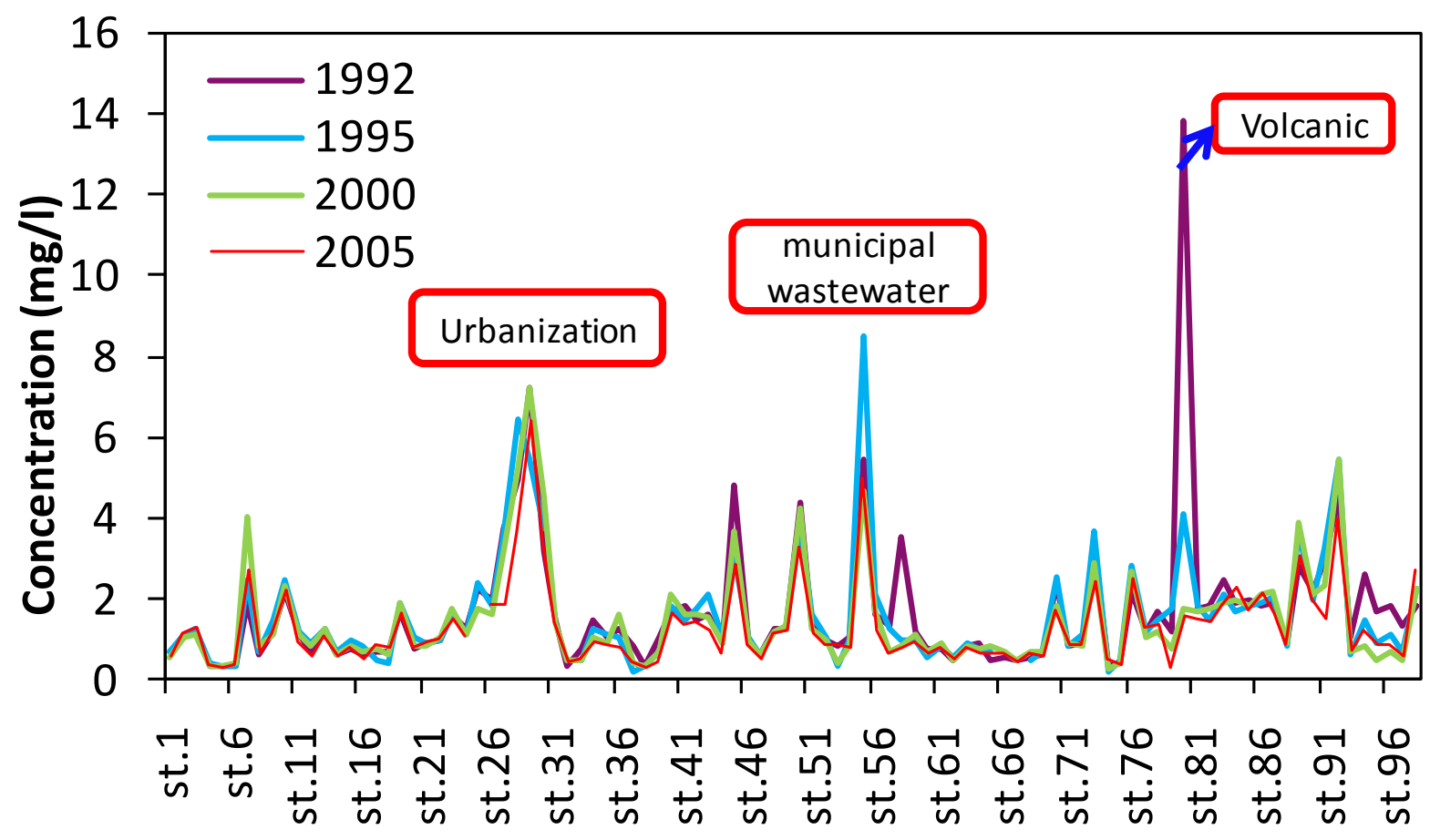

Fig.13 Spatial comparison of TN concentration. 


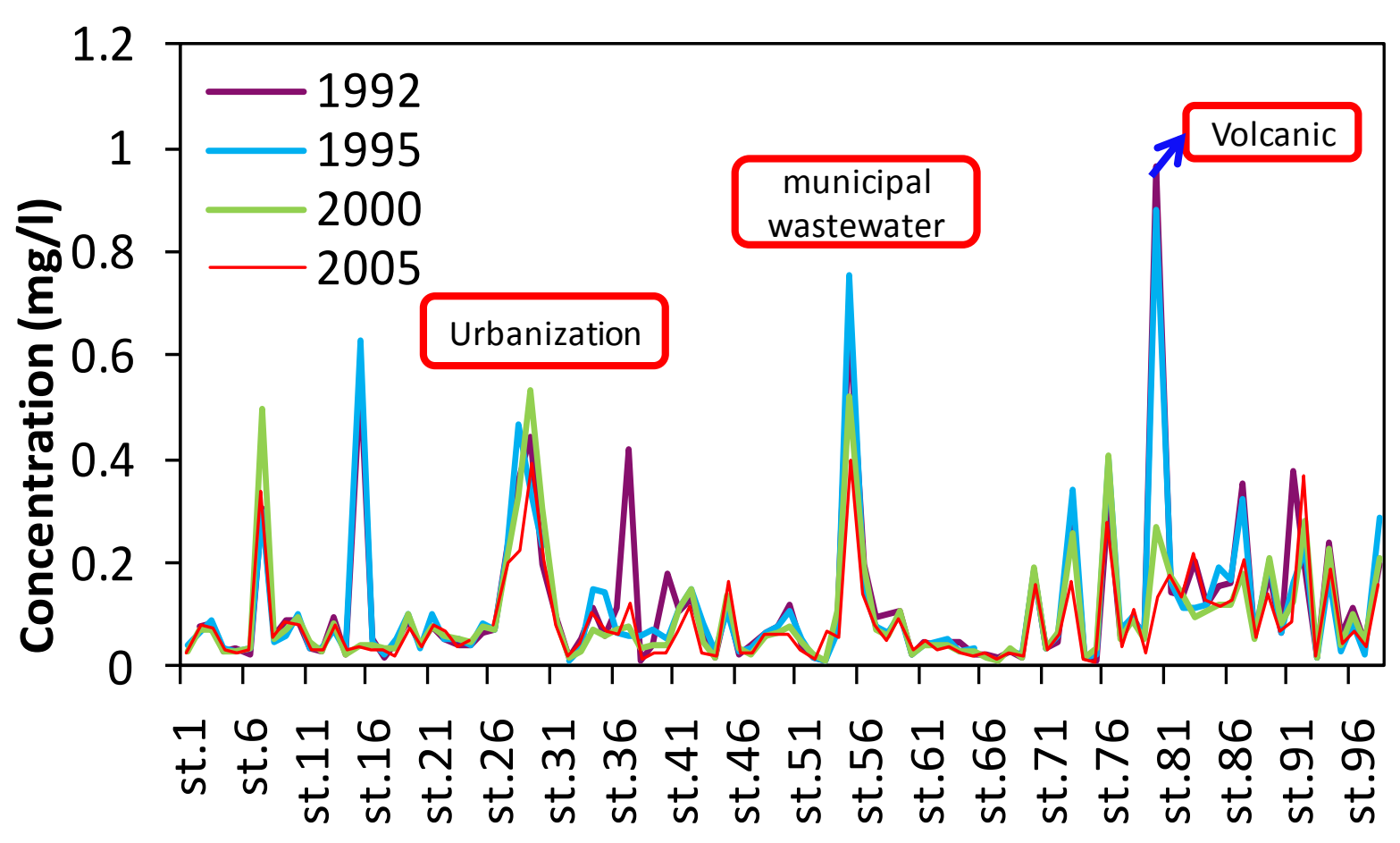

Fig.14 Spatial comparison of TP concentration. 


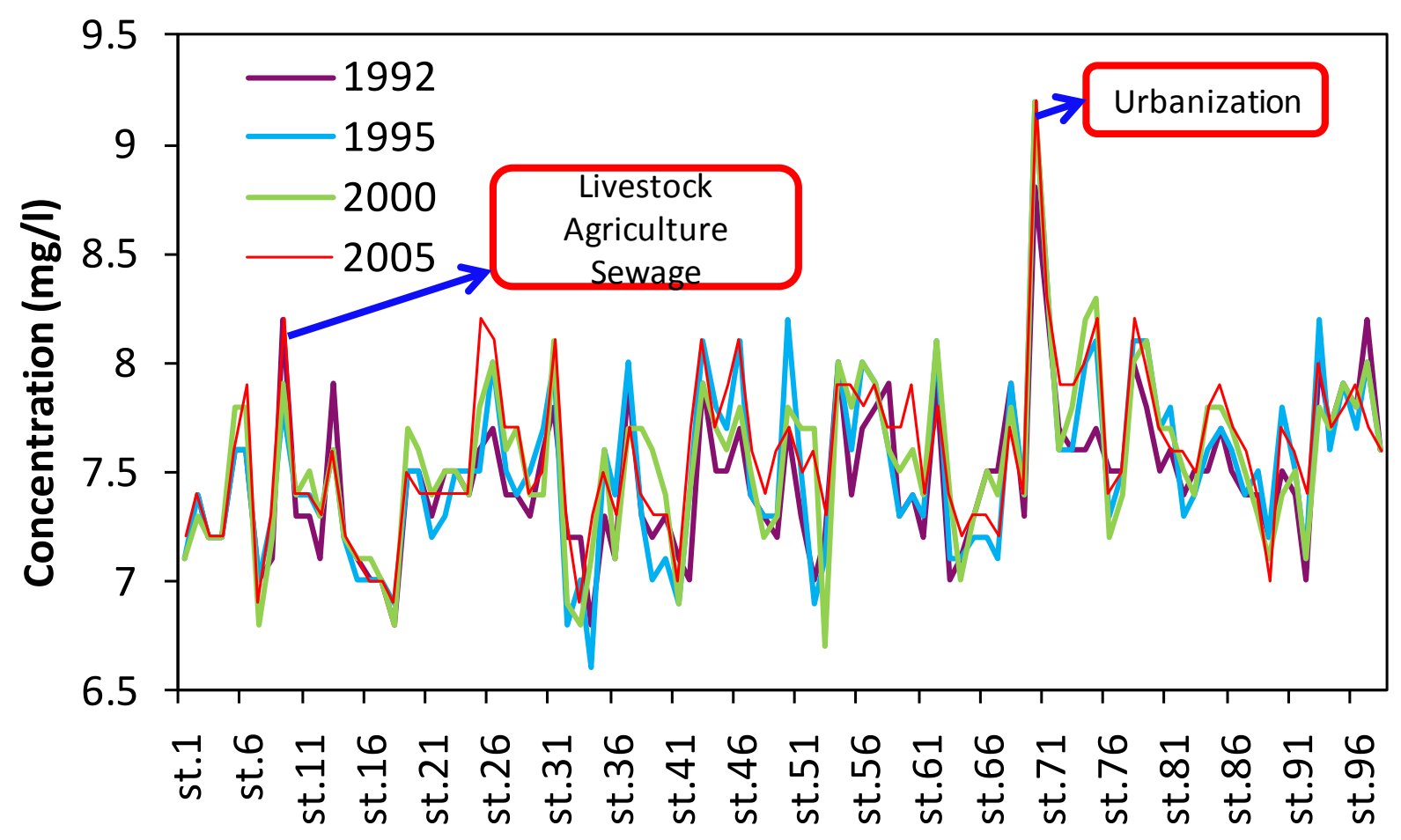

Fig.15 Spatial comparison of $\mathrm{pH}$ value. 